OPEN ACCESS

Edited by:

Bernard Malissen,

INSERM U1104 Centre

d'immunologie de Marseille-Luminy (CIML), France

Reviewed by:

Batu Erman,

Sabancı University, Turkey Haopeng Wang,

ShanghaiTech University, China

${ }^{*}$ Correspondence:

K. Scott Weber

scott_weber@byu.edu

Specialty section: This article was submitted to

T Cell Biology,

a section of the journal

Frontiers in Immunology

Received: 13 May 2020 Accepted: 30 November 2020 Published: 19 January 2021

Citation:

Johnson DK, Magoffin W, Myers SJ, Finnell JG, Hancock JC, Orton TS,

Persaud SP, Christensen KA and Weber KS (2021) CD4 Inhibits Helper

$T$ Cell Activation at Lower Affinity

Threshold for Full-Length

$T$ Cell Receptors Than Single

Chain Signaling Constructs.

Front. Immunol. 11:561889.

doi: 10.3389/fimmu.2020.561889

\section{CD4 Inhibits Helper T Cell Activation at Lower Affinity Threshold for Full- Length T Cell Receptors Than Single Chain Signaling Constructs}

\author{
Deborah K. Johnson ${ }^{1}$, Wyatt Magoffin ${ }^{1}$, Sheldon J. Myers ${ }^{1}$, Jordan G. Finnell ${ }^{2}$, \\ John C. Hancock ${ }^{1}$, Taylor S. Orton ${ }^{1}$, Stephen P. Persaud ${ }^{3}$, Kenneth A. Christensen ${ }^{2}$ \\ and $K$. Scott Weber ${ }^{1 *}$

\begin{abstract}
${ }^{1}$ Department of Microbiology and Molecular Biology, Brigham Young University, Provo, UT, United States, ${ }^{2}$ Department of Chemistry and Biochemistry, Brigham Young University, Provo, UT, United States, ${ }^{3}$ Division of Laboratory and Genomic Medicine, Department of Pathology and Immunology, Washington University in St. Louis, St. Louis, MO, United States
\end{abstract}

CD4 ${ }^{+} \mathrm{T}$ cells are crucial for effective repression and elimination of cancer cells. Despite a paucity of $C D 4^{+} T$ cell receptor $(T C R)$ clinical studies, $C D 4^{+} T$ cells are primed to become important therapeutics as they help circumvent tumor antigen escape and guide multifactorial immune responses. However, because $\mathrm{CD}^{+} \mathrm{T}$ cells directly kill tumor cells, most research has focused on the attributes of CD8 ${ }^{+}$TCRs. Less is known about how TCR affinity and CD4 expression affect $C D 4^{+} T$ cell activation in full length TCR (fITCR) and TCR single chain signaling (TCR-SCS) formats. Here, we generated an affinity panel of TCRs from CD4 ${ }^{+} T$ cells and expressed them in fITCR and three TCR-SCS formats modeled after chimeric antigen receptors (CARs) to understand the contributions of TCRpMHCll affinity, TCR format, and coreceptor CD4 interactions on $\mathrm{CD}^{+}{ }^{+} \mathrm{T}$ cell activation. Strikingly, the coreceptor CD4 inhibited intermediate and high affinity TCR-construct activation by Lck-dependent and -independent mechanisms. These inhibition mechanisms had unique affinity thresholds dependent on the TCR format. Intracellular construct formats affected the tetramer staining for each TCR as well as IL-2 production. IL-2 production was promoted by increased TCR-pMHCll affinity and the fITCR format. Thus, CD4 ${ }^{+} \mathrm{T}$ cell therapy development should consider TCR affinity, CD4 expression, and construct format.

Keywords: CD4, T cell receptor, affinity, chimeric antigen receptor, Lck, helper T cell

\section{INTRODUCTION}

$\mathrm{CD}^{+} \mathrm{T}$ cells are critical for tumor elimination through both indirect and direct mechanisms. Indirectly, $\mathrm{CD} 4^{+} \mathrm{T}$ cells target tumor cells by activating tumor-killing cells such as $\mathrm{CD} 8^{+} \mathrm{T}$ cells, macrophages, $\mathrm{B}$ cells, and natural killer cells $(1-4) . \mathrm{CD} 4^{+} \mathrm{T}$ cells have direct cytotoxic effects against tumor cells that express major histocompatibility complex II (MHCII) (1-4) and direct CD4 ${ }^{+} \mathrm{T}$ cell responses are less toxic to the patient than a $\mathrm{CD} 8^{+} \mathrm{T}$ cell response, especially when responding to overexpressed tumor associated antigens (TAA) (5). The presence of tumor-specific $\mathrm{CD} 4^{+} \mathrm{T}$ cells is 
correlated with improved patient survival following vaccination with cancer-associated peptides whether or not they are directly involved in tumor suppression (6-8). Furthermore, $\mathrm{CD}^{+}{ }^{+} \mathrm{T}$ cells can sustain an immune response when $\mathrm{CD} 8^{+}$-specific antigens are lost which otherwise might result in tumor escape (9). Despite these clear benefits, only one published clinical study (10) focuses on the immunotherapeutic benefits of $\mathrm{CD} 4^{+} \mathrm{T}$ cell receptors (TCRs) $(10,11)$.

$\mathrm{CD}^{+} \mathrm{T}$ cells are activated by interactions between the TCR and its cognate peptide presented on MHCII (pMHCII) (12). TCRs can detect a single amino acid change and distinguish between self-proteins and mutated neoantigens (11), uniquely suiting TCR-based therapies for specific tumor targeting. Furthermore, unlike antibody-based chimeric antigen receptors (CARs), which are limited to extracellular targets, TCRs can target intracellular antigens presented by MHC molecules (11). To rationally design optimal targeting strategies, it is essential to understand how the TCR:pMHC interaction impacts $\mathrm{T}$ cell responses. The relationship between TCR affinity and T cell activation is complex, but in general, $\mathrm{T}$ cell functional activity correlates with TCR binding affinity for pMHC (13-19). However, there are important nuances to this general theme. For example, tumor-associated antigens may be skewed towards lower-affinity clones due to thymic negative selection $(20,21)$, even the lowest-affinity TCRs can induce $\mathrm{T}$ cell proliferation, cytokine production and memory formation $(19,22)$. On the other end of the spectrum, high affinity TCRs have been shown to enhance immune responses in some cases (23) and attenuate responses in others (24-29), with some reports showing evidence of an affinity threshold beyond which increased affinity does not impact the magnitude of the response $(17,18)$. An additional consideration is that even when high-affinity TCRs are capable of heightened cytotoxicity and tumor control, these TCRs may be predisposed to autoimmunity (30). Thus, the optimal affinities for TCRs engineered against tumor-specific peptides may lie within a low or intermediate affinity $(14,24-26,30-36)$. As most affinity studies to date have focused on $\mathrm{CD} 8^{+}$TCRs, $\mathrm{CD} 4^{+} \mathrm{T}$ cell affinity thresholds are less well characterized.

The role of the CD4 coreceptor is an important consideration when associating TCR-pMHCII affinity to $\mathrm{CD}^{+} \mathrm{T}$ cell activation. CD4 binds to MHCII as part of the TCR complex and contributes to proximal TCR signaling, proving especially critical for $\mathrm{T}$ cell function when cognate $\mathrm{pMHC}$ ligands are limiting (<30 complexes) (37). TCR signaling dependence on CD4 is affected by the quality of TCR:pMHCII interaction and is unnecessary upon stimulation with optimal ligands (38). Thus, CD4 may be restricted to improving the TCR dwell time on pMHCII for lower affinity interactions (39). As CD4 ${ }^{+}$TCRs can function in natural killer cell lines without CD4 (40), CD4 may not have as great of an effect on $\mathrm{T}$ cell activation as CD8, particularly with high affinity TCRs.

To determine how TCR-pMHCII affinity and CD4 coreceptor interactions affect $\mathrm{CD}^{+} \mathrm{T}$ cell activation, we examined activation of the CD4 transgenic murine T cells LLO118 and LLO56 that are stimulated by the same Listeria monocytogenes epitope. These TCRs differ by 15 amino acids and recognize the
LLO $_{190-205}$ peptide presented by the MHCII molecule I-A ${ }^{\mathrm{b}}$ with similar affinity $(41,42)$. LLO118 has a more robust primary response and LLO56 has a more robust secondary response, indicating that TCR affinity is not the only parameter affecting activation in these cells. To examine the role of affinity in the activation responses of LLO56 and LLO118, we engineered an affinity panel of $\mathrm{CD}^{+}{ }^{+}$TCRs (ranging from $4 \mu \mathrm{M}$ to $200 \mathrm{nM}$ ) using yeast display $(43,44)$. After characterizing their affinity and avidity, the activation characteristics of two low affinity clones, two intermediate affinity clones, and one high affinity clone were examined in the full length TCR (flTCR) format or in three TCRSCS CAR formats (CD28- and 4-1BB-based second generation CARs, and CD28/4-1BB third generation CAR). T cell receptor single-chain signaling chimeric antigen receptors (TCR-SCS CARs) are an exciting potential therapeutic option and as $\mathrm{CD}^{+} \mathrm{T}$ cells are potent responders to cancer, we sought to understand how $\mathrm{CD}^{+}$TCRs respond to a variety of affinities. TCR-SCSs constructs avoid mispairing with endogenous TCR chains, which is an inherent risk for engineered flTCRs (45). CARs also produce more cytokines and are activated by higher antigen densities than flTCRs and may be more likely to ignore healthy cells with low amounts of TAAs, which may improve clinical outcomes (46-48).

We found that increased TCR affinity promotes production of IL-2 regardless of flTCR or TCR-SCS format. The flTCRs are more responsive to lower amounts of peptide stimulation, and contrary to $\mathrm{CD}^{+}$TCR findings (49), produce more cytokine than TCR-SCSs. While there are some observable trends dependent on second and third generation TCR-SCS CAR format, IL-2 production varies depending on whether the TCRs were engineered from the LLO56 or LLO118 TCRs. CD4 promotes the activation of low affinity flTCRs and TCR-SCSs, but CD4 is inhibitory in intermediate affinity flTCR and high affinity TCR-SCS CARs. The flTCR reaches CD4 inhibition at a lower affinity than TCR-SCSs, suggesting that flTCRs perceive a stronger initial activation signal. These findings suggest that therapeutic CD4 TCR development should consider construct features, TCR affinity, and coreceptor activation contributions when choosing or engineering therapeutic TCRs and cell lines.

\section{MATERIALS AND METHODS}

\section{Library Construction}

Yeast display allows for the external presentation and screening of large libraries of genetically altered proteins $(43,44)$. Single chain T cell receptor (scTCR) contain linked variable TCR $\alpha$ and $\beta$ domains but lack constant domains and any signaling domains. The scTCR constructs for LLO56 (residues 1-116) and LLO118 (residues 1-120) (Invitrogen) consist of the mature $\mathrm{V} \beta$ domain, a 13-aa linker (DAKKDAAKKDDAS) (50), followed by the mature $\mathrm{V} \alpha$ domain (LLO118 residues $1-112$ or LLO56 residues 1-113), and an N-terminal HA tag (PYDVPDYA). To display scTCRs on yeast, the constructs were placed in pCT302 (NheI and BglII) (Addgene plasmid \# 41845; http://n2t.net/ addgene:41845; RRID : Addgene_41845) (51). Stability clones 
were selected from scTCR transcripts replicated by error-prone PCR (Standard Taq, New England BioLabs, B9014S) (44). Affinity libraries were generated using site directed mutagenesis of 5 amino acids in the CDR3 $\beta$ region and splicing by overlap extension (SOE) PCR $(44,52)$ using LLO118 and LLO56 specific primers (Q5 High Fidelity DNA Polymerase, New England BioLabs M0491) (Supplementary Materials).

To generate yeast libraries, $150 \mathrm{ml}$ cultures of growth phase EBY100 yeast were collected and washed twice with $50 \mathrm{ml}$ icecold water and once with ice-cold electroporation buffer $(1 \mathrm{M}$ Sorbitol/1 $\mathrm{mM} \mathrm{CaCl} 2$ ) then resuspended in $0.1 \mathrm{M} \mathrm{LiAc} / 10 \mathrm{mM}$ DTT and incubated at $30^{\circ} \mathrm{C}$ and $225 \mathrm{rpm}$ for $30 \mathrm{~min}$ (53). Cells were washed with $50 \mathrm{ml}$ electroporation buffer, resuspended in $200 \mu$ lectroporation buffer and aliquoted with digested pCT302 backbone (NheI and BglII, 1,250 ng) and inserted $(6,250 \mathrm{ng})$ into $0.2 \mathrm{~mm}$ gap cuvettes then electroporated (2.5 $\mathrm{kV}$ and $25 \mu \mathrm{F}$ ). Cells were allowed to recover for $1 \mathrm{~h} \mathrm{in} 4 \mathrm{ml} 1 \mathrm{M}$ sorbitol:YPD media (1:1) and were resuspended in SD-CAA media and incubated for $2-3$ days at $30^{\circ} \mathrm{C}$ before quantification. Stability and affinity library sizes ranged from $1.1 \times 10^{7}$ to $1.9 \times 10^{9}$.

\section{Stability Clone Selection}

Libraries calculated to have at least 10 copies of each clone were placed in $5 \mathrm{ml} \mathrm{SG-CAA}$ media for $36-48 \mathrm{~h}$ to induce scTCR expression (54). To select stability clones, yeast libraries were incubated with either $2 \mu \mathrm{g} / \mathrm{ml}$ anti-mouse TCR Vo2 or antimouse TCR V $\beta 2$ phycoerythrin-conjugated antibodies (BioLegend, clone B20.1 and B20.6, respectively) in $5 \mathrm{ml}$ PBS $1 \%$ BSA for $2 \mathrm{~h}$ at $4^{\circ} \mathrm{C}$, washed with $15 \mathrm{ml}$ PBS $1 \%$ BSA and stained with $50 \mu \mathrm{l}$ anti-PE MicroBeads in $2 \mathrm{ml}$ PBS 1\% BSA (Millitenyi $130-048-801$ ) for $20 \mathrm{~min}$ at $4^{\circ} \mathrm{C}$. Labeled clones expressing properly folded $\mathrm{V} \alpha$ or $\mathrm{V} \beta$ were positively selected in magnetic LS columns (Millitenyi 130-042-401). Selected cells were grown in $3 \mathrm{ml} \mathrm{SD-CAA}$ media $(48 \mathrm{~h}$ ) before induction in SG-CAA (36-48 h). Each library was subjected to three rounds of growth and sorting, and the most stable clone identified via flow cytometry (BD Accuri C6). Stability clones were used as templates for subsequent stability or affinity libraries.

\section{Affinity Clone Selection}

To select affinity clones, induced yeast libraries were incubated with tetramer $\left(\mathrm{LLO}_{190-201} / \mathrm{I}-\mathrm{A}^{\mathrm{b}}\right)$ (I-A(b)CC (NEKYAQAYPNVS), NIH 22201), and sorted like stability clones. To isolate high affinity clones, libraries were exposed to an increasingly strict temperature and incubation regimen. Initially, libraries were subjected to high concentrations of tetramer $(13.0 \mu \mathrm{g} / \mathrm{ml})$, high temperatures $\left(37^{\circ} \mathrm{C}\right)$, and long incubation times $(3 \mathrm{~h})$, and in later rounds, combinations of lower tetramer concentrations $(3.25 \mu \mathrm{g} / \mathrm{ml})$, lower temperatures (RT or $4^{\circ} \mathrm{C}$ ), and shorter incubation times $(1 \mathrm{~h})$ were used to isolate the clones with highest affinity. Each library was column sorted three times. Isolated clones with increased tetramer binding were identified via flow cytometry (BD Accuri C6).

\section{Tetramer Dissociation}

Each affinity and stability clone $\mathrm{K}_{\mathrm{D}}$ was determined through tetramer dissociation (55). Aliquots of $1 \times 10^{6}$ induced cells were stained with $100 \mu \mathrm{l}$ of various concentrations of $\mathrm{LLO}_{190-201} / \mathrm{I}-\mathrm{A}^{\mathrm{b}}$ tetramer $(0.152 \mathrm{nM}$ to $12.16 \mathrm{nM})$ for $1.5 \mathrm{~h}$ at room temperature and quantified via flow cytometry. Tetramer binding was assessed as MFI of positive population and normalized to the highest recorded MFI using FlowJo. $\mathrm{K}_{\mathrm{D}}$ was defined as $50 \%$ maximum binding concentration (55).

\section{Tetramer Decay}

Half-life $\left(\mathrm{t}_{1 / 2}\right)$ was determined by staining $3 \times 10^{6}$ cells of each affinity clone with $6.5 \mu \mathrm{g} / \mathrm{ml}$ of tetramer for $1.5 \mathrm{~h}$ at room temperature (56). Samples were washed three times in PBS 1\% BSA to remove excess tetramer. Following an initial timepoint measurement, $90 \mu \mathrm{l}$ of $0.1 \mu \mathrm{g} / \mathrm{ml}$ or $1 \mu \mathrm{g} / \mathrm{ml}$ anti-mouse MHC class II (I-A/I-E) (clone: M5/114.15.2, eBioscience) was added and the decrease of tetramer binding was quantified at various time points $(2,5,10,15,20,30,45$, and $60 \mathrm{~min})$ by placing $10 \mu \mathrm{l}$ of cells into $90 \mu \mathrm{l}$ of buffer and running immediately on the flow cytometer.

\section{scTCR Expression, Refolding, and Purification}

The following protocol was modified from Garcia et al[61]. Briefly, scTCR constructs were cloned into pET28a (Novagen) using NcoI and SacI restriction sites. Constructs were expressed in BL21 T7 Express E. coli (New England Biolabs) and protein expression was induced for $4 \mathrm{~h}(0.4 \mathrm{mM}$ isopropyl $\beta$-Dthiogalactoside). Cells were lysed with $1 \mathrm{mg} / \mathrm{ml}$ lysozyme (ThermoFisher Scientific), $5 \mathrm{mM} \mathrm{MgCl} 2,1 \mu \mathrm{l} / \mathrm{ml}$ DNase I (Promega), 1\% Triton-X 100, and $10 \mathrm{mM}$ dithiothreitol followed by two rounds of sonification (Branson Digital Sonifer) for $1 \mathrm{~min}$ at $0.5 \mathrm{~s}$ alternations at $40 \%$ power. Fifty to $200 \mathrm{mg}$ of inclusion body slurry was dissolved in $1 \mathrm{ml}$ of $7 \mathrm{M}$ $\mathrm{GnHCl}$ and $10 \mathrm{mM}$ beta-mercaptoethanol. Four hundred $\mathrm{ml}$ of $2 \mathrm{M} \mathrm{GnHCl}, 50 \mathrm{mM}$ Tris-HCl, 2mM GSH, $0.2 \mathrm{mM}$ GSSG, and $0.1 \% \mathrm{NaAz}$ were dripped into dissolved inclusion bodies for 2-4 $\mathrm{h}$ at $4^{\circ} \mathrm{C}$. Then $2-2.5 \mathrm{~L}$ of $200 \mathrm{mM} \mathrm{NaCl}, 50 \mathrm{mM}$ Tris- $\mathrm{HCl}$, and $0.1 \% \mathrm{NaAz}$ were dripped for $24 \mathrm{~h}(1.5 \mathrm{ml} / \mathrm{min}$ speed $)$ at $4^{\circ} \mathrm{C}$. Following an additional $24 \mathrm{~h}$ spinning at $4^{\circ} \mathrm{C}$, the refolded TCR solution was vacuum filtered with $0.22 \mu \mathrm{m}$ PES membranes (Olympus Plastics), and then concentrated in an Amicon 8400 unit (Ultracel $10 \mathrm{kdal}$ Ultrafiltration Discs) under 55psi $\mathrm{N}_{2}$. Once the volume was reduced to $50-100 \mathrm{ml}$ of refolded scTCRs, the samples were again filtered with $0.45 \mu \mathrm{m}$ CA-membrane and GF prefilter syringe filter and purified by FPLC (AKTAstart) on a HisTrap column (GE Life Sciences). Purified scTCRs were concentrated using Amicon centrifugal filters (Ultra 4 10k) and quantified by Pierce BCA Protein Assay kit (Thermo Scientific).

\section{Bio-Layer Interferometry (BLI)}

BLI experiments were performed with an Octet RED96. Streptavidin (SA) biosensors (FortéBio) were hydrated and equilibrated in 1x HEPES buffered saline (HBS, $50 \mathrm{mM}$ HEPES, $150 \mathrm{mM} \mathrm{NalCl}$, pH 7.2), $2 \mathrm{mM} \mathrm{CaCl}_{2}, 1 \mathrm{mM} \mathrm{MgCl}_{2}, 1$ $\mathrm{mg} / \mathrm{ml}$ milk, $0.1 \%$ Tween, and $0.02 \% \mathrm{NaN}_{3}$. SA sensors were loaded with $2.0 \mu \mathrm{g} / \mathrm{ml}$ biotinylated $\mathrm{LLO}_{190-201} / \mathrm{I}-\mathrm{A}^{\mathrm{b}}$ monomer or $\mathrm{DQB}_{187-101} / \mathrm{I}^{\mathrm{A}} \mathrm{A}^{\mathrm{b}}$ monomer to $1.0-2.0 \mathrm{~nm}$. Loaded biosensors were equilibrated in assay buffer until baseline was achieved. 
scTCR association was probed in wells with assay buffer (stability clones $2,1,0.5,0.25,0.125,0.061 \mu \mathrm{M}$; affinity clones 800,400 , $200,100,50$, and $25 \mathrm{nM}$, or $20,10,5,2.5,1.25$, and $0.625 \mathrm{nM}$ ) with a blank reference-subtraction well for 400-600 s. Ideal concentration range spanned one log above and below the $\mathrm{K}_{\mathrm{D}}$ where possible; however, this range had to be optimized depending on the sensitivity of the assay, and on the amount of protein available. Matching of sample and baseline imidazole and milk concentrations (through serial dilution of sample buffer into baseline wells) was critical for detection of scTCR binding. Blocking with bovine serum albumin increased non-specific binding while milk efficiently blocked NSB. Dissociation was observed in baseline assay buffer (600-1,200 s). Assays were run at $30^{\circ} \mathrm{C}$ with a plate shake speed of $1,000 \mathrm{rpm}$.

Data was collected at $5 \mathrm{~Hz}$, using 20-point signal averaging and analyzed using custom kinetic analysis. Due to non-specific binding at the later stages of the association and dissociation steps, $\mathrm{K}_{\mathrm{D}}$ was calculated by extracting and selecting the data points from the initial association to determine $\mathrm{k}_{\mathrm{obs}}(2-100 \mathrm{~s}$ depending on the affinity of the constructs), plotting concentration vs rate, and then plotting those slopes against scTCR concentration and estimating $\mathrm{k}_{\mathrm{assoc}}$ from the slope. $\mathrm{k}_{\text {dissoc }}$ is the slope of concentration vs rate of the dissociation step data (2-100 s depending on the affinity of the constructs). $\mathrm{K}_{\mathrm{D}}$ was determined by dividing $\mathrm{k}_{\text {diss }} / \mathrm{k}_{\mathrm{assoc}}$ and $\mathrm{t}_{1 / 2}=\ln 2 / \mathrm{k}_{\mathrm{D}}$.

\section{Cell Culturing}

All $58^{-/-} \mathrm{T}$ cell hybridoma cell lines were cultured in RPMI 1640, $10 \% \mathrm{FBS}, 2 \mathrm{~g} / \mathrm{L} \mathrm{NaHCO}_{3}(23.8 \mathrm{mM})$, HEPES (4.2mM), L-glutamine (3.24 mM), 1\% Penn-strep and split 1:5 or 1:10 every 2-3 days. Platinum Ecotrophic cells (Plat E) were cultured in DMEM, 10\% FBS, $1 \%$ pen-strep, $1 \mu \mathrm{g} / \mathrm{ml}$ puromycin, and $10 \mu \mathrm{g} / \mathrm{ml}$ blasticidin and split 1:4 every other day.

\section{Retroviral Transduction of T Cell Hybridomas}

Affinity mutations were cloned into four possible constructs: full length TCRs (flTCRs), and three TCR-single chain signaling formats based on chimeric antigen receptor (CAR) formats (second generation 4-1BB and CD28 CARs, and third generation 4-1BB/CD28 CAR). Inserts were cloned into pMSCV-IRES-GFP II (pMIGII) (Addgene plasmid \# 52107; http://n2t.net/ addgene:52107; RRID : Addgene_52107) using MfeI and XhoI (GenScript) (57). All constructs were led by a Kozak sequence and either $\mathrm{V} \alpha 2$ signal peptide (MDKILTASFLLL GLHLAGVSGQ) and an additional V $\beta 2$ signal peptide (MWQFCILCLCVLMASVATD) for flTCRs or high affinity M33 $3^{\text {rd }}$ gen CAR signal peptide (MLLALLPVLGIHFVLRDAQA) for all TCR-SCS CAR constructs (58). flTCR constructs have a P2A cleavage domain (GSGATNFSLLKQAGDVEENPG) (59) between C $\alpha 2$ and V $\beta 2$ domains. All TCR-SCS and flTCR were linked to GFP by an IRES domain and GFP expression mirrors TCR construct expression in cell lines.

Vectors were transfected into Plat E packaging cells grown overnight in 6-well plates with TransIT-VirusGEN (Mirus, MIR 6703). Forty-eight hours later, $1 \mathrm{ml}$ of viral supernatant was mixed with $1 \mathrm{ml}$ of $1 \times 10^{6} 58^{-/-} \mathrm{CD}^{-}$or $58^{-/-} \mathrm{CD} 4^{+}$cells in a 6well plate and spinfected for $2 \mathrm{~h}$ at $30^{\circ} \mathrm{C}$ at $1,000 \mathrm{G}$ (acceleration 6, brake 2). After $48 \mathrm{~h}$ recovery, clones $\mathrm{V} \beta 2, \mathrm{~V} \alpha 2$, and $\mathrm{GFP}^{+}$ expression was checked by flow cytometry. Clones with under 85-90\% GFP expression were sorted 1-3 times with magnetic LS columns (Miltenyi Biotec, 130-042-401) using $10 \mu \mathrm{l}$ V $\beta 2-\mathrm{PE}$ antibodies and $10 \mu \mathrm{l}$ anti-PE MicroBeads (Miltenyi Biotec, 130048-801) per manufacturer specifications. Clones were checked for TCR expression after each sort round. CD4T ${ }^{+}$and CD4T $\mathrm{T}^{+}$ $\Delta$ bind (60) were cloned into pMIGII (MfeI/XhoI) and retrovirally transfected into existing $58^{-/-} \mathrm{CD} 4^{-} \mathrm{flTCR}$ and TCR-SCS clones and sorted for $>95 \%$ CD4 expression (CD4 PE-Cy7, GK1.5, Biolegend) by flow sorting (BD FACSAria II). Twenty-five thousand cells were stained with respective antibodies or tetramer for all affinity and stability measurements and measured with flow cytometry (BD Accuri).

\section{T Cell Hybridoma Peptide-Specific Activation and IL-2 Measurement}

$2.8 \times 10^{4} \mathrm{~T}$ cell hybridoma clones were incubated with $2.8 \times 10^{5}$ splenocytes (1:10) isolated from BL6.C57 mice with varying amounts $\left(10^{-8} \mathrm{M}\right.$ to $\left.10^{-3} \mathrm{M}\right)$ of peptide $\left(\mathrm{LLO}_{190-205}\right.$, GenScript) in $75 \mu \mathrm{l} \mathrm{58^{-/- }}$ media in 96 well plate for $24 \mathrm{~h}$. IL-2 production was measured using an IL-2 ELISA kit (KIT) and measured on a microplate reader. This study was approved and carried out in accordance with principles of the Basel Declaration and recommendations of Brigham Young University's Institutional Animal Care and Use Committee (IACUC protocol \#18-0708).

\section{Statistical Analysis}

Statistical analysis was performed via one-way ANOVA with Tukey's multiple comparison test ( $\mathrm{p}<0.05$ was significant, no alpha adjustments required). Half-life $\left(t_{1 / 2}\right)$ was determined by linear regression between time point 0 and the time point where no tetramer binding was detected (56). To determine the $\mathrm{K}_{\mathrm{D}}$, we fit the data with a non-linear curve, based on one site-specific binding kinetics (55). EC $_{50}$ was determined with Sigmoidal, 4PL, $\mathrm{X}$ is $\log$ (concentration) least squares fit. Standard deviation is reported for each value. All analyses were conducted in GraphPad Prism.

\section{RESULTS}

\section{Yeast Displayed TCR Panel Has Varied Affinities}

Murine transgenic helper T cells LLO56 and LLO118 bear TCRs, which recognize the same naturally occurring Listeria monocytogenes peptide $\left(\mathrm{LLO}_{190-205}\right)$ presented on MHCII (I$\mathrm{A}^{\mathrm{b}}$ ). The LLO56 and LLO118 TCR bind cognate pMHC with similar affinity $(27.4 \mu \mathrm{M}$ and $28.3 \mu \mathrm{M}$, respectively), yet have unique primary and secondary responses to TCR stimulus (summarized in Supplemental Table S1) (41, 42). LLO56 and LLO118 differ from each other by 15 amino acids located in the complementarity determining regions (CDR) CDR3 $\beta$ (amino acids 96-108, 111, 116, 118), CDR2 $\beta$ (aa52), and CDR3 $\alpha$ (aa93) 
regions (Supplemental Figure S1). To further elucidate the effects of TCR-pMHCII affinity on $\mathrm{CD}^{+} \mathrm{T}$ cell activation, the variable regions of LLO56 and LLO118 (Figure 1A) were used as templates for generating a panel of single-chain TCRs (scTCRs) with low (wild type), intermediate, and high affinities. scTCR libraries generated by random mutagenesis and expressed via yeast surface display (Figure 1B) were selected for protein folding stability through magnetic column sorting (Figure 1C). scTCR expression levels vary according to yeast cell cycle stage and can result in multiple peaks. The left peak is the non-displaying fraction and there can be intermediate and high displaying yeast (61). Vß2 stability mutations were conserved between constructs while $\mathrm{V} \alpha 2$ stability mutations clustered in known stability hotspots (Supplemental Figure S1). To generate affinity mutants, five amino acids in the stability mutants LLO56 $6_{\text {low }}$

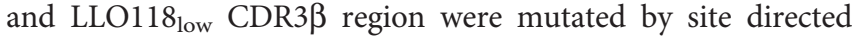
mutagenesis and selected for improved binding affinity for LLO $_{190-201} / \mathrm{I}_{-} \mathrm{A}^{\mathrm{b}}$ tetramers by magnetic column sorting. Increases in scTCR affinity cannot be explained by increases in scTCR expression, as HA and TCR $\alpha$ and TCR $\beta$ antibody binding remained the same across each experiment (Figure 1B). Additionally, none of the isolated stability or affinity mutants bound significantly to a non-target peptide tetramer $\left(\mathrm{DQB} 1_{87-101} / \mathrm{I}-\mathrm{A}^{\mathrm{b}}\right)$, indicating that the increase in tetramer binding is due to peptide-specific binding and not increased affinity for I-A ${ }^{\mathrm{b}}$ alone (Figure 1D). Affinity mutant LLO56 $6_{\text {int }}$
A

Aga-2 $\quad H A \quad V B 2 \quad$ linker $\quad V \alpha 2$
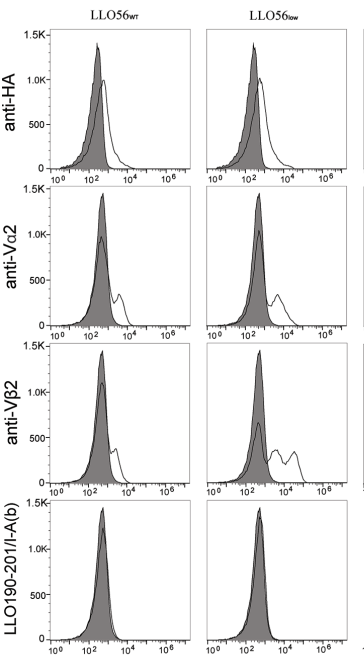

D

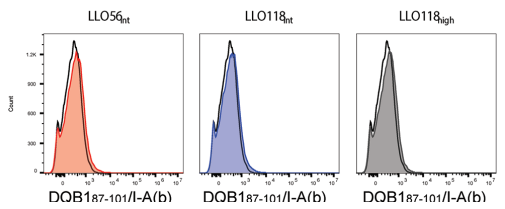

B

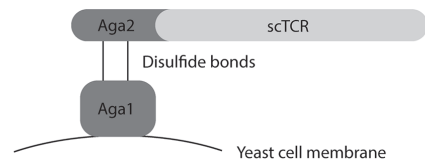

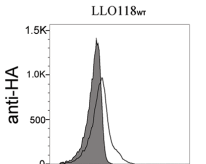
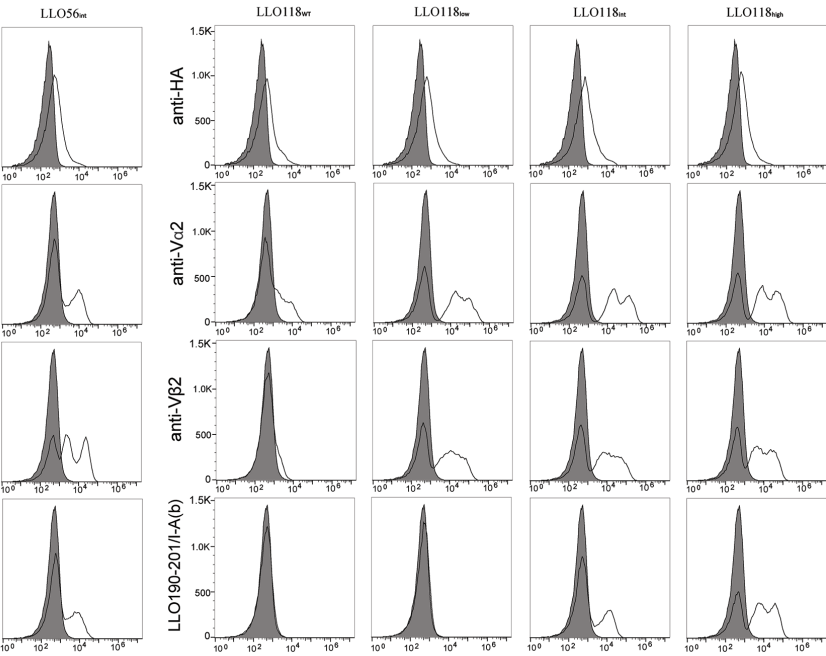

$\mathbf{E}$

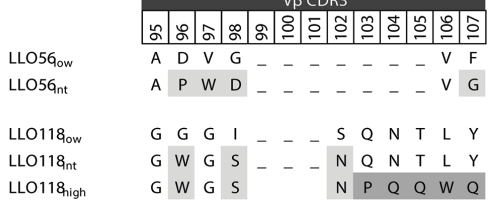

FIGURE 1 | LLO118 and LLO56 stability and affinity maturation by yeast display. (A) Schematic of single-chain TCR (scTCR) which includes TCR $\alpha$ and $\beta$ variable domains $(V \alpha$ and $V \beta)$ spliced from TCR constant domains and connected with a 13 amino acid linker. Aga-2 is the yeast mating protein that displays the scTCR on yeast cell membrane. Each construct contains an HA tag for antibody detection. (B) Schematic of a scTCR displayed on the cell surface via yeast display. The yeast mating protein Aga1 binds to the Aga2-scTCR fusion protein and enables the display of these proteins on the cell surface. Large scTCR libraries can be generated, stained with antibodies or peptide-MHC tetramers, and yeast clones containing scTCRs with improved stability or affinity characteristics can be identified and selected. (C) Wild type LLO118 and LLO56 were engineered for improved stability and higher affinity by yeast surface display. Clones with stability mutations were selected for using monoclonal anti- $\mathrm{V} \alpha$ or anti- $\mathrm{B}$ antibodies. The surface displayed constructs were then selected for improved affinity using the peptide $\mathrm{MHC}$ tetramer LLO $190-201 / /-A^{b}$. Staining of wild type clones LLO56 $W_{W T}$ and LLO118 $8_{W T}$ (first and fourth columns), stability clones LLO56 low and LLO118 $8_{\text {low }}$ (second and fifth columns), intermediate affinity clones LLO56 int $_{\text {and }}$ LLO118 int $_{\text {(third and sixth columns) and high affinity clone LLO118 }}$ high (seventh column) is shown. Stains include antibodies against the HA epitope (first row), V $\alpha 2$ (second row), and VB2 (third row), or LLO $190-201 / \mathrm{l}-\mathrm{A}^{\mathrm{b}} \mathrm{pMHCll}$ tetramer (fourth row). Gray-filled histogram represents cells-only control. Histograms are representative of $n>3$ experiments. (D) Affinity clones were incubated with saturating amounts of non-target tetramer (DQB1 $87-101 /$ $I-A^{\mathrm{b}}$ ). Histograms compare cells only (black clear) with affinity clones (colored, shaded). (E) V 32 CDR3 mutations that confer increases in affinity. CDR3 $\beta$ regions are hypervariable; therefore, gaps mark the length of other known V 32 CDR3 $\beta$ regions. First round of affinity selection (light gray) for all affinity clones while second round of affinity selection (dark gray) applies only to LLO118 high. 
with four CDR3 $\beta$ mutations (Figure 1E) bound $\mathrm{LLO}_{190-201} / \mathrm{I}-\mathrm{A}^{\mathrm{b}}$ 1.5 log better than stability mutant LLO56 $6_{\text {low }}$ (Figure 1C). Affinity mutant LLO118 $8_{\text {high }}$ bound to the $\mathrm{LLO}_{190-201} / \mathrm{I}-\mathrm{A}^{\mathrm{b}}$ tetramer $1.0-\log$ better than affinity mutant LLO118 int $_{\text {and } 2.5-}$ $\log$ better than stability mutant LLO118 $8_{\text {low }}$ (Figure 1C). LLO118 $8_{\text {int }}$ had three CDR3 $\beta$ mutations and LLO118 $A_{\text {high }}$ had five additional CDR3 $\beta$ mutations (Figure 1E). While LLO56 int and LLO118 $8_{\text {high }}$ mutants were used as templates for mutant libraries of the complementary determining region 3 of the $\alpha$ chain $(\mathrm{CDR} 3 \alpha)$, no further clones with increased-affinity for $\mathrm{LLO}_{190-201} / \mathrm{I}-\mathrm{A}^{\mathrm{b}}$ tetramer were isolated, suggesting that CDR3 $\beta$ is primarily responsible for $\mathrm{LLO}_{190-201}$ peptide interactions for

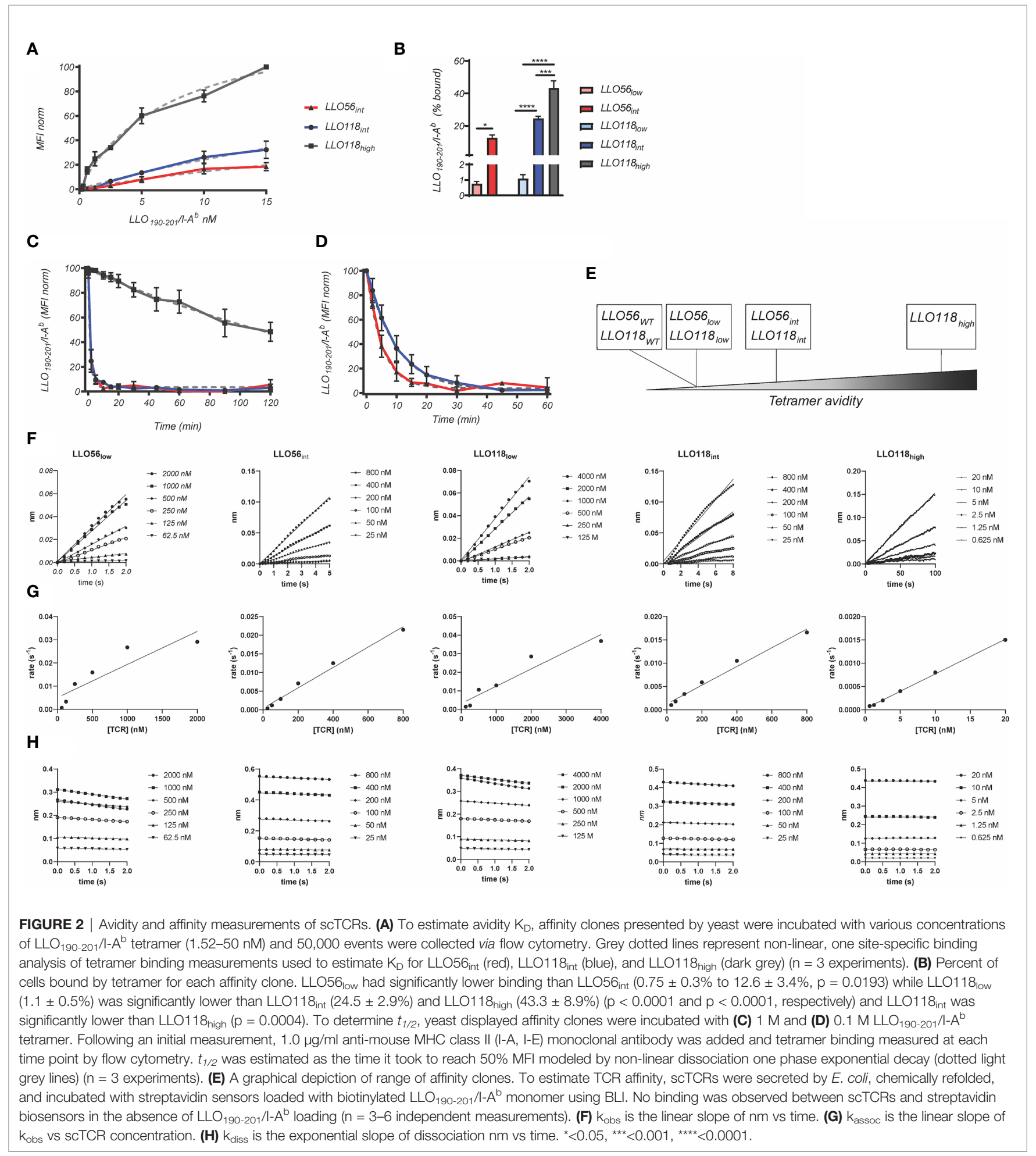


TABLE 1 | Comparison between scTCR clones avidity (Tetramer) and affinity $K_{d}$ (Bio-layer Interferometry).

\begin{tabular}{|c|c|c|c|c|c|c|c|c|}
\hline & \multicolumn{4}{|c|}{ Tetramer (Avidity) } & \multicolumn{4}{|c|}{ Bio-layer Interferometry (Affinity) } \\
\hline & $t_{1 / 2}(m)$ & $r^{2}$ & $\mathbf{K}_{\mathbf{D}}$ & $r^{2}$ & $\mathrm{k}_{\text {assoc }}\left(\mathrm{M}^{-1} \mathrm{~s}^{-1}\right)$ & $\mathbf{k}_{\text {dissoc }}\left(\mathbf{s}^{-1}\right)$ & $t_{1 / 2}(s)$ & $K_{\mathrm{D}}$ \\
\hline LLO56 low & & & & & $18300 \pm 7000$ & $0.053 \pm 0.020$ & $14.5 \pm 5.7$ & $2.9 \pm 0.7 \mu \mathrm{M}$ \\
\hline LLO56 $_{\text {int }}$ & 1 & 0.97 & $39.2 \pm 46.7 \mathrm{nM}$ & 0.82 & $27600 \pm 3000$ & $0.018 \pm 0.0007$ & $422.0 \pm 163.1$ & $66.2 \pm 39.8 \mathrm{nM}$ \\
\hline LLO118 low & & & & & $10200 \pm 1500$ & $0.043 \pm 0.004$ & $16.1 \pm 1.3$ & $4.3 \pm 0.7 \mu \mathrm{M}$ \\
\hline LLO118 int & 1 & 0.97 & $44.8 \pm 52.3 \mathrm{nM}$ & 0.96 & $20000 \pm 1400$ & $0.025 \pm 0.007$ & $28.8 \pm 7.4$ & $1.3 \pm 0.3 \mu \mathrm{M}$ \\
\hline LLO118 & 165 & 0.76 & $7.33 \pm 1.37 \mathrm{nM}$ & 0.87 & $73000 \pm 8600$ & $0.002 \pm 0.0007$ & $460.0 \pm 176.8$ & $20.0+/-13.9 \mathrm{nM}$ \\
\hline
\end{tabular}

these specific TCRs. It is important to note that the stability clones initially isolated from yeast libraries relied on a frameshift mutation at the stop codon that added 19-amino acids from the yeast expression vector to the carboxy end of $\mathrm{V} \alpha 2$ (RSDNNSVDVTKSTLFPPYF). While LLO56 $6_{\text {low }}$ and LLO56 $6_{\text {int }}$ successfully retained stability and affinity gains without the 19 amino acids, several attempts to create new LLO118 stability and affinity clones without the additional amino acids were unsuccessful. Therefore, the stabilizing 19 amino acids were maintained for LLO118 clones. Other studies have utilized TCR formats that express constant domains in order to maintain scTCR folding while adding additional affinity mutations to the TCRs, therefore this observation was not unexpected (62-64).

The multivalent binding avidity of each clone was determined by $\mathrm{LLO}_{190-201} / \mathrm{I}-\mathrm{A}^{\mathrm{b}}$ tetramer titration $(150 \mathrm{pM}-15.00 \mathrm{nM})$ of scTCR expressed on yeast (Figure 2A). Avidities ranged from the highest clone LLO118 $8_{\text {high }}(7.30 \mathrm{nM})$, to intermediate avidity clones LLO56 int $(39.20 \mathrm{nM})$ and LLO118 $8_{\text {int }}(44.80 \mathrm{nM})$ (Figures 2A, B and Table 1). Stability clones LLO56 $6_{\text {low }}$ and LLO118 $8_{\text {low }}$ were excluded from these analyses because binding was undetectable even at the highest concentrations of $\mathrm{LLO}_{190-}$ ${ }_{201} / \mathrm{I}-\mathrm{A}^{\mathrm{b}}$ tetramer (Figure 2B). Tetramer decay analysis of clones displayed on yeast determined that the multivalent half-life for LLO118 $8_{\text {high }}\left(t_{1 / 2}=165 \mathrm{~min}, \mathrm{r}^{2}=0.76\right)$ was 165 -times longer than LLO118 $_{\text {int }}$ and LLO56 ${ }_{\text {int }}\left(t_{1 / 2}=\sim 1\right.$ min each, $\mathrm{r}^{2}=0.97$ each) suggesting that the increased avidity of LLO118 $8_{\text {high }}$ is predominantly due to a lengthened off-rate (Figure 2C). A second round of tetramer decay with lower levels of $\mathrm{MHC}$ inhibiting-antibody better resolved the half-lives of LLO118 $\left(t_{1 / 2}=6.7\right.$ mins, $\left.r^{2}=0.97\right)$ and LLO56 $6_{\text {int }}\left(t_{1 / 2}=3.5\right.$ mins, $\left.\mathrm{r}^{2}=0.98\right)$ (Figure 2D), indicating that LLO118 $8_{\text {int }}$ has a longer dissociation rate than LLO56 $6_{\text {int }}$. The resulting panel of TCRs provides a range of tetramer avidities ranging from high to low (Figure 2E).

While tetramer avidity measurements may be more physiologically relevant as multiple TCR-pMHCs interact simultaneously during $\mathrm{T}$ cell activation, TCR-pMHC affinity measurements provide a standard measurement to compare between TCR systems. Therefore, TCR:pMHC affinity was measured by quantifying the interaction of monomeric refolded scTCR with monomeric $\mathrm{LLO}_{190-201} / \mathrm{I}-\mathrm{A}^{\mathrm{b}}$ via bio-layer interferometry. Due to non-specific binding at the later stages of the association and dissociation steps, the $\mathrm{K}_{\mathrm{D}}$ was calculated manually by extracting the data from the early measurements; $\mathrm{k}_{\mathrm{obs}}$ slopes ((Figure 2F) were plotted against scTCR concentration (Figure 2G) and $\mathrm{k}_{\text {assoc }}$ estimated from the slope. $\mathrm{k}_{\text {diss }}$ is the slope of dissociation graphs (Figure $2 \mathbf{H}$ ). $\mathrm{K}_{\mathrm{D}}$ was determined by dividing $\mathrm{k}_{\text {diss }} / \mathrm{k}_{\text {assoc }}$. LLO118 $8_{\text {high }}(20.0 \pm 13.9 \mathrm{nM})$ $\mathrm{K}_{\mathrm{D}}$ was 215 -fold higher than LLO118 $8_{\text {low }}(4.3 \pm 0.7 \mu \mathrm{M})$ (Table 1). Intriguingly, while LLO $118_{\text {int }}$ and LLO56 $6_{\text {int }}$ avidity measurements were similar, their affinity measurements were markedly different $\left(20\right.$-fold). LLO118 $8_{\text {int }}(1.3 \pm 0.3 \mu \mathrm{M})$ was only 3 -fold higher affinity than LLO118 $8_{\text {low }}$ and LLO56 $6_{\text {int }}(66.2 \pm 39.8$ $\mathrm{nM}$ ) was 43 -fold higher than LLO56 $6_{\text {low }}(3.8 \pm 1.3 \mu \mathrm{M})$ (Table 1).

\section{Construct Format Impacts Surface Expression and pMHCII-Affinity Independently}

To quantitatively assess the effects of TCR-pMHC affinity, CD4, and construct format on helper T cell activation, TCR constructs were retrovirally transduced into murine $\mathrm{T}$ cell hybridomas, $58^{-/-}$ $\mathrm{CD}^{-}\left(\mathrm{CD} 4^{-}\right)$and $58^{-/-} \mathrm{CD}^{+}\left(\mathrm{CD}^{+}\right)$, which do not express endogenous TCRs. $58^{-/-} \mathrm{T}$ cell hybridoma cell lines have been a useful cell line for examining TCR kinetics and IL-2 production prior to primary cell line observations $(47,49,65,66)$. LLO56 $6_{\text {low }}$ and LLO56 $6_{\text {int }}$ were placed in the three TCR-SCSs formats, and LLO56 $_{\text {WT }}$ and LLO56 $6_{\text {int }}$ were placed in flTCR constructs without stability mutations (Figures 3A, B, Supplemental Figures S2S5). Because of the necessity of the additional 19 amino acids, LO118 $8_{\text {low }}$, LLO118 $8_{\text {int }}$, and LLO118 $8_{\text {high }}$ affinity changes were not transferred to flTCR constructs. LLO118 $8_{\text {low }}$, LLO118 $8_{\text {int }}$, and LLO118 $8_{\text {high }}$ were placed in three TCR-SCSs formats based on commonly used second and third generation chimeric antigen receptor (CAR) formats (Figures 3A, B, Supplemental Figures S2-S4). The transduced cell lines were sorted with anti-V $\beta 2$ antibodies via magnetic column selection for $>85 \% \mathrm{GFP}^{+}$and TCR expression (Figure 3C).

TCR stable surface expression varied by individual constructs. As assessed by V $\beta 2$ expression, flTCR constructs were less stably expressed than all TCR-SCS constructs perhaps due to CD3 subunit availability, while TCR-SCS CD28 constructs were the most stably expressed format for both LLO56 and LLO118 constructs (Figure 3D). While most construct expression was equitable between $\mathrm{CD}^{-}$and $\mathrm{CD} 4^{+}$cell lines, TCR-SCS 4-1BB constructs had the most expression variability between constructs as CD4 expression destabilized LLO118 $8_{\text {low }}$ and LLO118 $_{\text {int }}$ TCR-SCS $4-1 \mathrm{BB}$ expression $(\mathrm{p}=0.0018$ and $\mathrm{p}=$ 0.0429 , respectively) (Figure 3D). CD4 $4^{-}$LLO11 $8_{\text {high }} 4-1 \mathrm{BB}$ constructs were less stable than CD4- LLO118 ${ }_{\text {low }} 4-1 \mathrm{BB}$ and LLO118 $_{\text {int }} 4-1 \mathrm{BB}(\mathrm{p}=0.0030$ and $\mathrm{p}=0.0002$, respectively) (Figure 3D). CD $4^{+}$LLO118 $8_{\text {high }} 4-1 \mathrm{BB}$ was also less stable than either LLO118 $8_{\text {low }}$ or LLO118 $8_{\text {int }}(\mathrm{p}=0.0285$ and $\mathrm{p}=0.0493$ ) (Figure 3D). Overall CD4 expression did not significantly destabilize $3^{\text {rd }}$ gen constructs except LLO118 $8_{\text {low }}(\mathrm{p}=0.0401)$ 
A

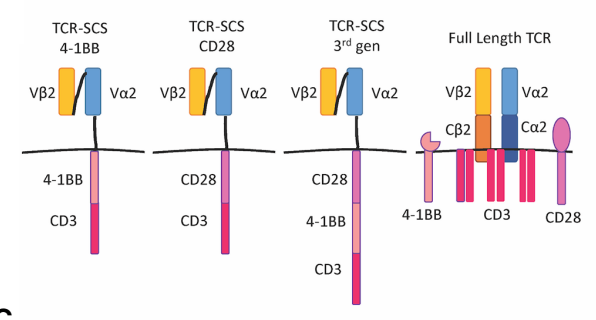

C

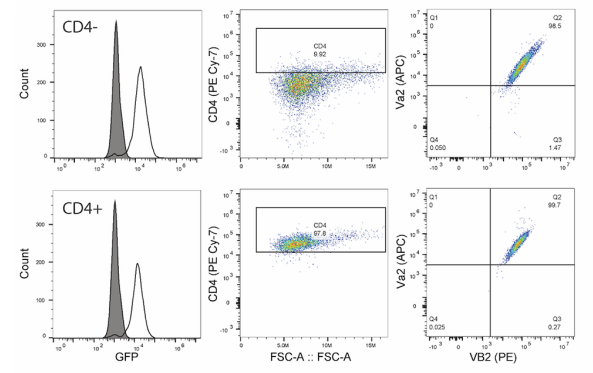

B

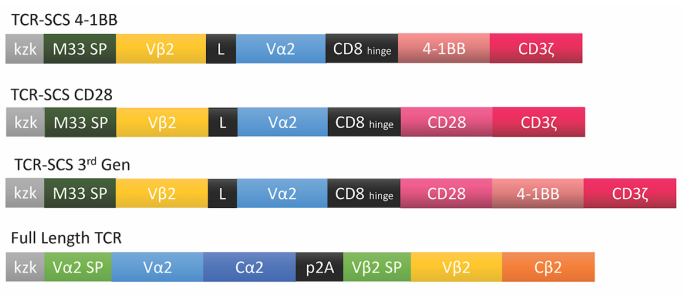

D

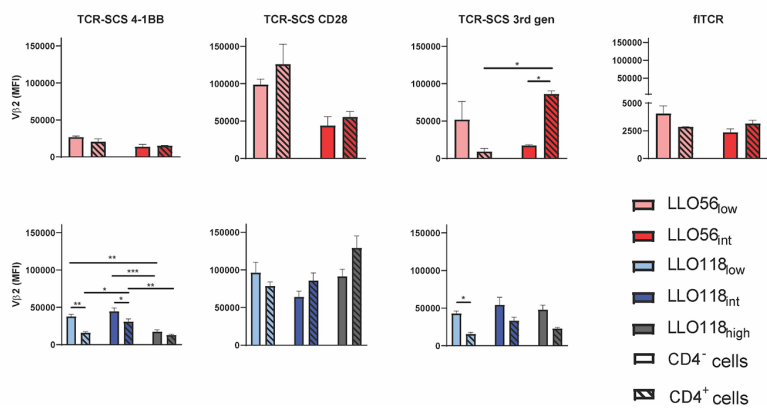

FIGURE 3 | TCR-SCS and fITCRs are stably expressed in CD4- and CD4 ${ }^{+}$T cell hybridomas. (A) Diagrams depicting the fITCR formats and three TCR-SCS formats in the cell membrane. All TCR-SCS constructs have signaling coreceptor CD3 in addition to the signaling domains of coreceptors CD28 and/or 4-1BB. (B) TCR constructs are produced from a bicistronic IRES-GFP vector and GFP expression mirrors TCR construct expression in cell lines. In addition to the P2A cleavage domain, TCR-SCS formats rely on TCR M33 signal peptide (67), whereas the fITCR has dedicated signal peptides for $\alpha 2$ and $\beta 2$ to increase localization of both chains to the surface. The CD8 hinge acts as an intermembrane domain. (C) An example of TCR-SCS expression in CD4 $4^{-}$(top) and CD4 ${ }^{+}$(bottom) T cell

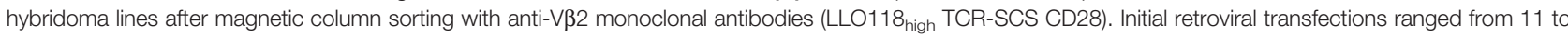
$85 \%$ efficiency. Grey peaks in GFP histograms represent a GFP' cells-only control. GFP+ cells were gated for CD4 expression and V $\alpha 2$ and V $\beta 2$ expression. Representative of $n=3$ measurements of 20,000 cells via flow cytometry. (D) Mean fluorescent intensity (MFI) of VB2 was used as a proxy for stable expression of constructs. Constructs were expressed in $\mathrm{CD}^{-}$(solid bars) and CD4 (hatched bars) T cell hybridomas. Representative of $\mathrm{n}=3$ measurements of 20,000 cells via flow cytometry. ${ }^{*}<0.05,{ }^{* *}<0.01,{ }^{* \star *}<0.001$.

and LLO56 int where CD4 stabilized VB2 expression $(\mathrm{p}=0.0109)$ (Figure 3D). GFP expression does not correlate with expression differences of the constructs for each format between $\mathrm{CD} 4^{-}$and $\mathrm{CD}^{+}$expression nor expression differences between TCR (Supplemental Figures S6).

Tetramer titrations were used to approximate the avidity of each flTCR or TCR-SCS construct. Intriguingly, the intracellular format strongly influenced the avidity of each intermediate and high affinity TCR construct (Figure $\mathbf{4 A}$ ). There is no clear link across all clones between stable V $\beta 2$ expression and construct avidity, although the most stable constructs-TCR-SCS CD28-did have the highest apparent avidity (LLO56 $6_{\text {int }}$ and LLO118 ${ }_{\text {high }}$ ) (Figure 4A). Overall, CD4 expression (dotted lines) did not affect the avidity of the constructs, excepting LLO118 $8_{\text {int }}$ and LLO118 $8_{\text {high }} 3^{\text {rd }}$ gen constructs where CD4 lessened and heightened avidity, respectively (Figure $\mathbf{4 A}$ ). The MFI measured for each clone at $10^{-8} \mathrm{M}$ (a non-saturated concentration) were used to compare avidity differences between affinity clones. LLO56 $4-1 \mathrm{BB}, 3^{\text {rd }}$ gen and flTCR constructs had no significant differences between LLO56 $_{\text {low }}$ and LLO56 $6_{\text {int }}$ (Figure 4B). This may be due to the small affinity differences between LLO56 $6_{\text {low }}$ and LLO56 $6_{\text {int }}$ as measured in tetramer and bio-layer interferometry assays. However, LLO118 $3^{\text {rd }}$ gen constructs also did not show affinitydependent avidity changes, thus intracellular signaling domains may also affect the avidity of extracellular scTCRs. There were significant avidity differences for LLO118 4-1BB clones; CD4LLO11 $8_{\text {high }} 4-1 \mathrm{BB}$ had significantly better avidity than its cognate $\mathrm{CD}^{+}$pairing $(\mathrm{p}=0.0004)$, and was also significantly higher than CD4 ${ }^{-}$LLO118 $_{\text {low }}$ and LLO118 $8_{\text {int }} 4-1 \mathrm{BB}(\mathrm{p}=0.0003$ and $\mathrm{p}=0.0092$, respectively) (Figure 4B). Additionally, TCR-SCS CD28 constructs for both LLO56 and LLO118, which are the most stably expressed constructs (Figure 3D), showed increased MFI by increasing TCR affinity (Figure 4B). LLO56 int $_{\text {CD28 }}$ had significantly greater avidity than $\mathrm{LLO})_{\text {low }} \mathrm{CD} 28\left(\mathrm{CD} 4^{-} \mathrm{p}=0.0122\right.$ and $\mathrm{CD} 4^{+} \mathrm{p}=$ 0.0086), as did LLO118 $8_{\text {high }}$ CD28 compared to LLO118 $8_{\text {low }}$ (CD4 $\mathrm{p}=0.0129$ and $\mathrm{CD}^{+} \mathrm{p}=0.0113$ ) (Figure 4B). IL-2 production is not correlated with GFP intensity (Supplemental Figure S6). Taken together, while there is no systematic correlation, this data suggests that construct stability may influence avidity measurements, as CD28 clones had the highest stability and avidity, and confirms that generally, $\mathrm{CD} 4$ does not affect perceived avidity.

\section{CD4 Inhibits High Affinity TCR IL-2 Production}

To assess the effects of TCR-pMHCII affinity, CD4 expression, and format on T cell activation we measured IL-2 expression in response to increasing agonist peptide concentrations. As anticipated, LLO56 $6_{\text {low }}$ flTCR IL-2 production improved with 
A
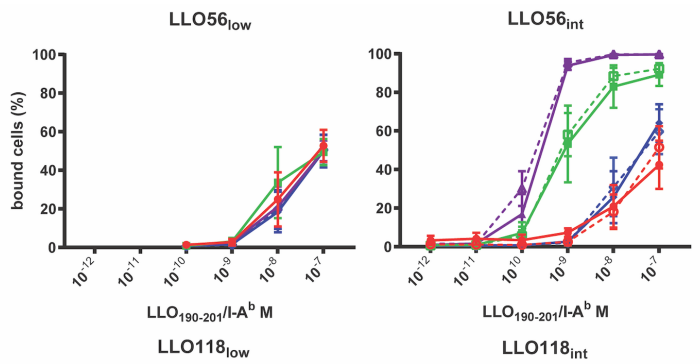

$\rightarrow$ TCR-SCS 3rd gen

$\rightarrow$ TCR-SCS 4-1BB

$\mp$ TCR-SCS CD28

$\rightarrow$ fITCR

- CD4 cells

--- $\mathrm{CD}^{+}$cells
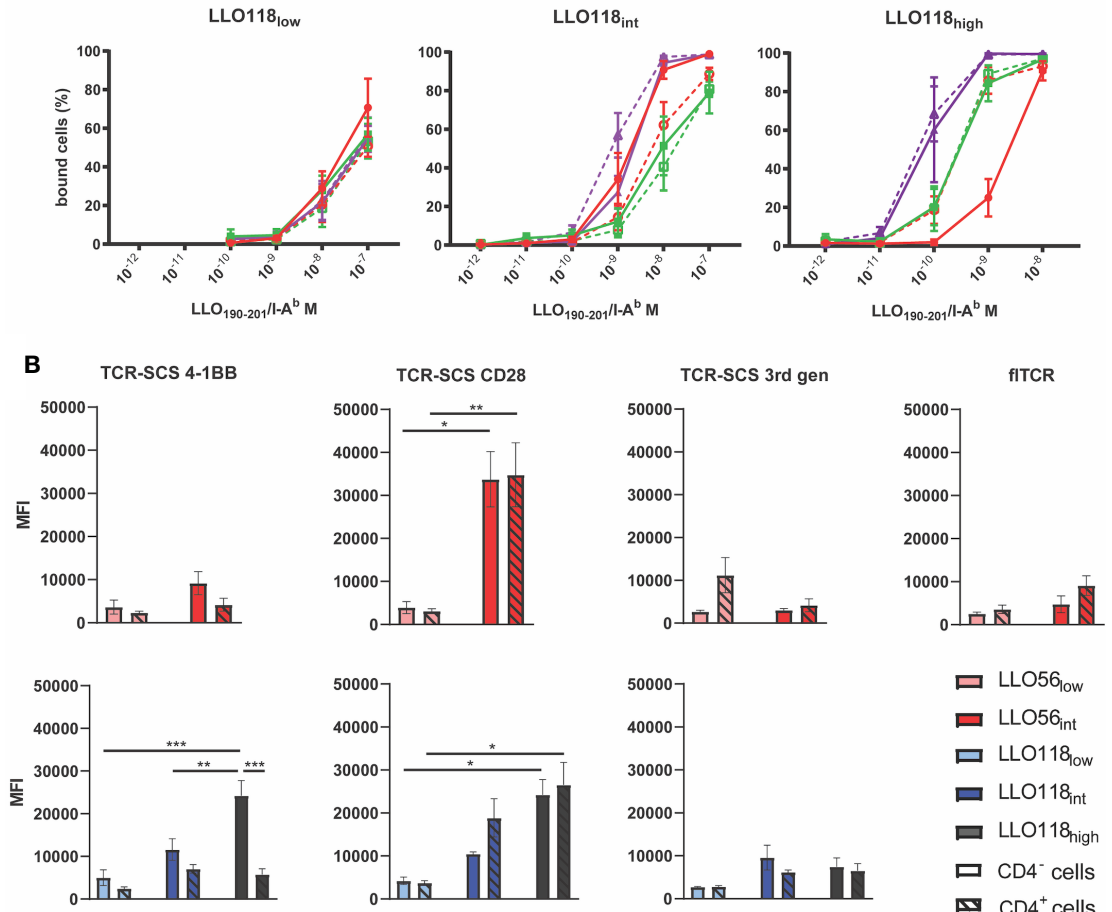

$$
\begin{aligned}
& \text { ロ } \mathrm{LLO56}_{\text {low }} \\
& \text { 口 LLO56 int } \\
& \text { ロ LLO118 } \\
& \text { 口 LLO118 } \\
& \text { 口 LLO118 } \\
& \text { 口 } \mathrm{CD} 4^{-} \text {cells } \\
& \text { Ш } \mathrm{CD}^{+} \text {cells }
\end{aligned}
$$

FIGURE 4 | TCR-pMHCll avidity is affected by construct format. (A) fITCR or TCR-SCS expressing cell lines were incubated with varying amounts of LLO ${ }_{190-201} / l_{-}$ $\mathrm{A}^{\mathrm{b}}$ tetramer $\left(10^{-7} \mathrm{M}\right.$ to $10^{-12} \mathrm{M}$ ) at room temperature for $2 \mathrm{~h}$. Each TCR-format pair expressed in CD4 ${ }^{-}$cell lines (solid lines) and CD4 ${ }^{+}$cell lines (dotted lines) have similar affinities, whereas each unique construct format alters avidity of a single TCR. Representative of three independent measurements of 20,000 cells via flow cytometry. (B) Tetramer MFI measurements of $10^{-8} \mathrm{M}$ separated by TCR and format where CD4- cell lines (solid bars) and CD4 ${ }^{+}$cell lines (hashed bars) are paired. ${ }^{*}<0.05,{ }^{* *}<0.01,{ }^{* \star *}<0.001$.

CD4 expression, but CD4 expression unexpectedly reduced IL-2 production for LLO56 $6_{\text {int }}$ flTCR (Figure 5A). Despite the inconsistent role of CD4, flTCRs produced significantly more IL-2 at all affinity levels (Figure 5A) and were at least 1-log fold more sensitive to peptide than all TCR-SCSs (Figures 5B-D). IL2 production for $\mathrm{CD}^{-}$clones rose with increased TCR affinity for most constructs except $3^{\text {rd }}$ gen constructs; LLO56 $6_{\text {int }} 3^{\text {rd }}$ gen failed to produce more cytokines than LLO56 $6_{\text {low }} 3^{\text {rd }}$ gen (Figure 5B) and LLO118 $8_{\text {high }}$ 3rd gen that produced less IL-2 than LLO $118_{\text {int }} 3^{\text {rd }}$ gen (Figure 5C). This pattern of uneven gains across affinity and base TCR was also observed for 4-1BB constructs (Figures 5D, E); while LLO56 4-1BB did see gains across affinity (Figure 5D), LLO118 4-1BB constructs had limited affinity gains across the affinity gradient (Figure 5E). CD4- ${ }^{-}$LLO56 $_{\text {int }}$ CD28 and CD4 $4^{-}$LL0118 ${ }_{\text {high }}$ CD28 produced more IL-2 than other TCR-SCS constructs which suggested that their heightened stable expression may promote IL-2 production (Figures 5F, G). As noted in low affinity scTCR clones (LLO56 $6_{\text {low }} 3^{\text {rd }}$ gen and CD28, and LLO118 $8_{\text {low }} 3^{\text {rd }}$ gen) (Figures 5B, C, F), $\mathrm{CD}^{+}$and $\mathrm{CD}^{-}$clones may also respond uniquely across antigenic concentrations, however this is likely an artifact due to variability or the limits of detection.

While CD4 promoted the activation of all low affinity clones, it unexpectedly suppressed IL-2 production for all intermediate and high affinity constructs (Figure 5). The magnitude of IL-2 suppression is greatly dependent on whether the construct was a flTCR or TCR-SCS construct. For example, while LLO56 $6_{\text {low }}$ flTCR IL-2 production was assisted by CD4 expression, LLO56 $_{\text {int }}$ flTCR IL-2 production was reduced 2.2-fold ( $\mathrm{p}=$ 0.0707 ) at $10^{-3} \mathrm{M}$ peptide stimulation (Supplemental Figure S7). In contrast, only one TCR-SCS had such a mild IL-2 reduction. $\mathrm{CD}^{+} \mathrm{LL} 56_{\text {int }} 4-1 \mathrm{BB}$ IL-2 production was reduced by 2.5 -fold ( $\mathrm{p}=0.1551$ ) (Supplemental Figure S7). The IL-2 production for the other intermediate and high affinity TCR-SCS 
A

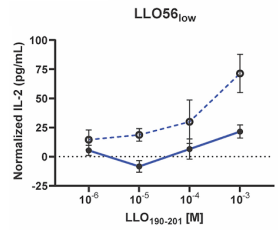

B
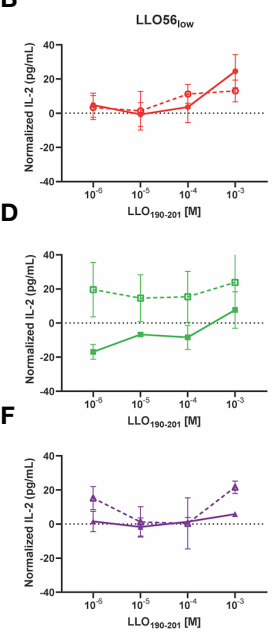

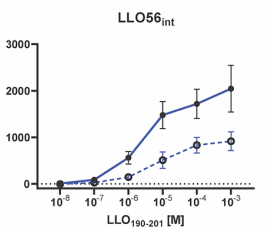

C
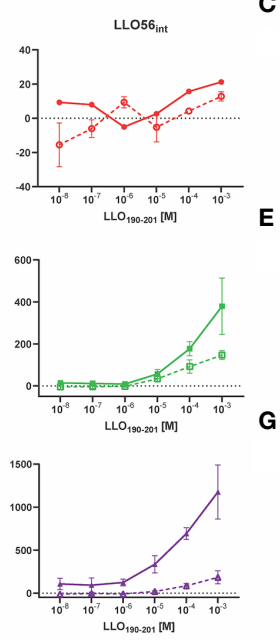
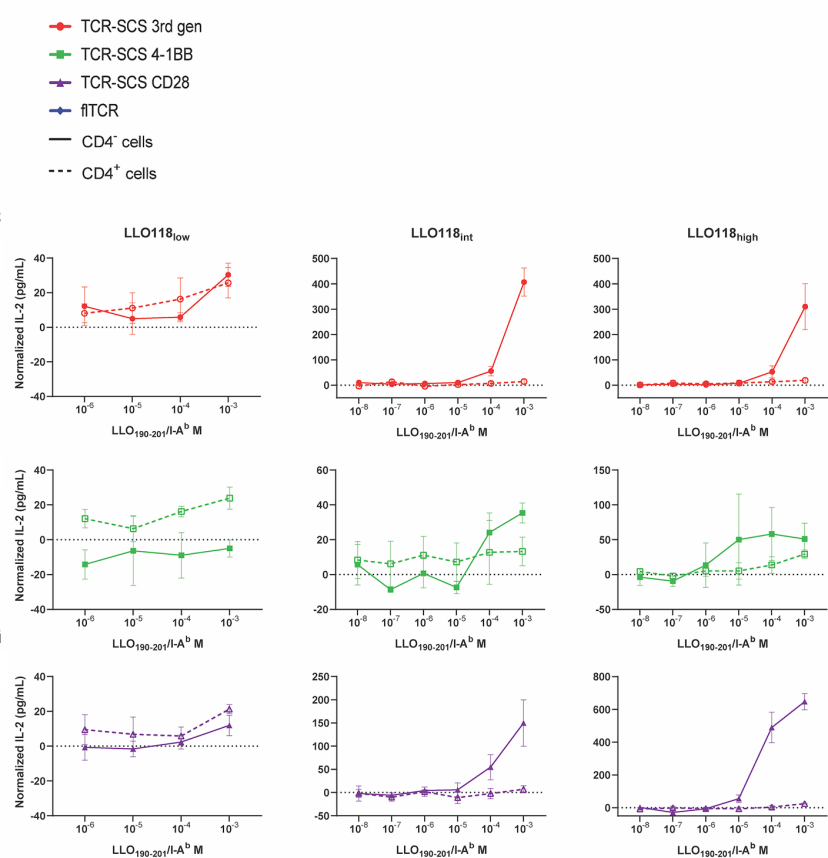
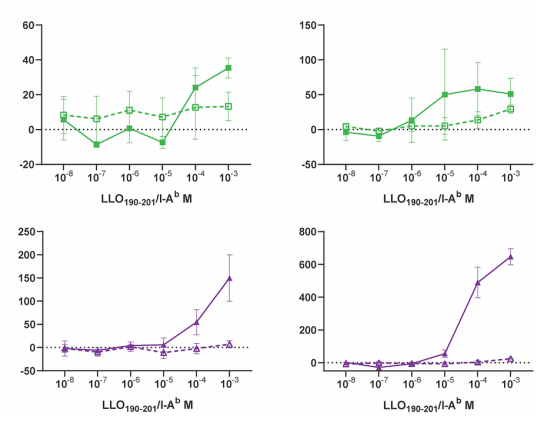

FIGURE 5 | CD4 inhibits IL-2 production of intermediate and high affinity TCRs. CD4- (solid lines) and CD4 ${ }^{+}$(dotted lines) T cell hybridoma cell lines were incubated with various concentrations of LLO $190-201$ peptide $\left(10^{-8} \mathrm{M}\right.$ to $\left.10^{-3} \mathrm{M}\right)$ presented by BL6/C57 splenocytes for $24 \mathrm{~h}$. IL-2 production was measured by ELISA. Each sample was normalized by subtracting baseline IL-2 production from T cell hybridoma/splenocytes controls incubated without peptide. (A) LLO56 flTCRs, (B) LLO56 $3^{\text {rd }}$ gen TCR-SCSs, (C) LLO118 $3^{\text {rd }}$ gen TCR-SCSs, (D) LLO56 4-1BB TCR-SCSs, (E) LLO118 4-1BB TCR-SCSs, (F) LLO56 CD28 TCR-SCSs, and (G) LLO118 CD28 TCR-SCSs. ELISAs run $n=3$ times.

constructs was intermediately reduced for LLO56 int CD28 (6.4fold, $\mathrm{p}=0.0104)$, and severely reduced for LLO118 $8_{\text {int }} 3^{\text {rd }}$ gen (28.1-fold, $\mathrm{p}=0.0004)$, LLO118 ${ }_{\text {int }}$ CD28 (21.2-fold, $\left.\mathrm{p}=0.0400\right)$, LLO $118_{\text {high }} 3^{\text {rd }}$ gen $(16.5$-fold, $\mathrm{p}=0.0051)$, and LLO118 $8_{\text {high }}$ CD28 (25.9-fold, p < 0.0001) (Supplemental Figure S7). Peptide sensitivity, defined as the lowest concentration where IL-2 response exceeds baseline IL-2 production, was equitable between $\mathrm{CD}^{-}$and $\mathrm{CD}^{+}$for constructs LLO56 ${ }_{\text {int }}$ flTCR, LLO56 $3^{\text {rd }}$ gen, and LLO56 $6_{\text {int }} 4-1 \mathrm{BB}$ (Figures $5 \mathrm{~A}$, D, Table 2), but delayed 1-log fold for LL056 int CD28 and at least 2-log fold for all LLO118 $8_{\text {int }}$ and LLO118 $8_{\text {high }}$ constructs (Figures 5C, E-G, Table 2). This suggests that CD4 reduced peptide sensitivity for most TCR-SCS constructs, possibly in a TCR-dependent manner.

\section{Lck Sequestration by CD4 Inhibits Some TCR IL-2 Production}

Lck is an early proximal signaling kinase that colocalizes to the cytoplasmic domain of CD4 $(68,69)$. If Lck is poorly recruited to the TCR-pMHCII synapse, then $\mathrm{T}$ cell activation may be diminished (49). We hypothesized that our high affinity clones may poorly recruit CD4-Lck to the immunological synapse, decreasing activation, and therefore reducing IL-2 production as observed in $\mathrm{CD} 4^{+}$intermediate and high affinity clones. To parse out the potential contributions of CD4-Lck sequestration, CD4-MHCII interactions, and any CD4-dependent inhibition, we expressed a selection of our flTCR and TCR-SCS clones in four $58^{-/-} \mathrm{T}$ cell hybridoma lines $(49,60)$. LLO56 TCR-SCS $3^{\text {rd }}$

TABLE 2 | Approximated peptide sensitivity for responding clones.

Peptide sensitivity

\begin{tabular}{|c|c|c|c|c|c|c|}
\hline & \multicolumn{2}{|c|}{ LLO56int } & \multicolumn{2}{|c|}{ LL0118int } & \multicolumn{2}{|c|}{ LL0118high } \\
\hline fITCR & 1.00E-06 & 1.00E-06 & & & & \\
\hline $4-1 B B$ & 1.00E-05 & 1.00E-05 & 1.00E-04 & ND & 1.00E-06 & 1.00E-04 \\
\hline CD28 & 1.00E-05 & 1.00E-04 & 1.00E-04 & ND & 1.00E-05 & $N D$ \\
\hline
\end{tabular}

CD4 expression inhibited the production of IL-2 for most clones (marked in light red). 


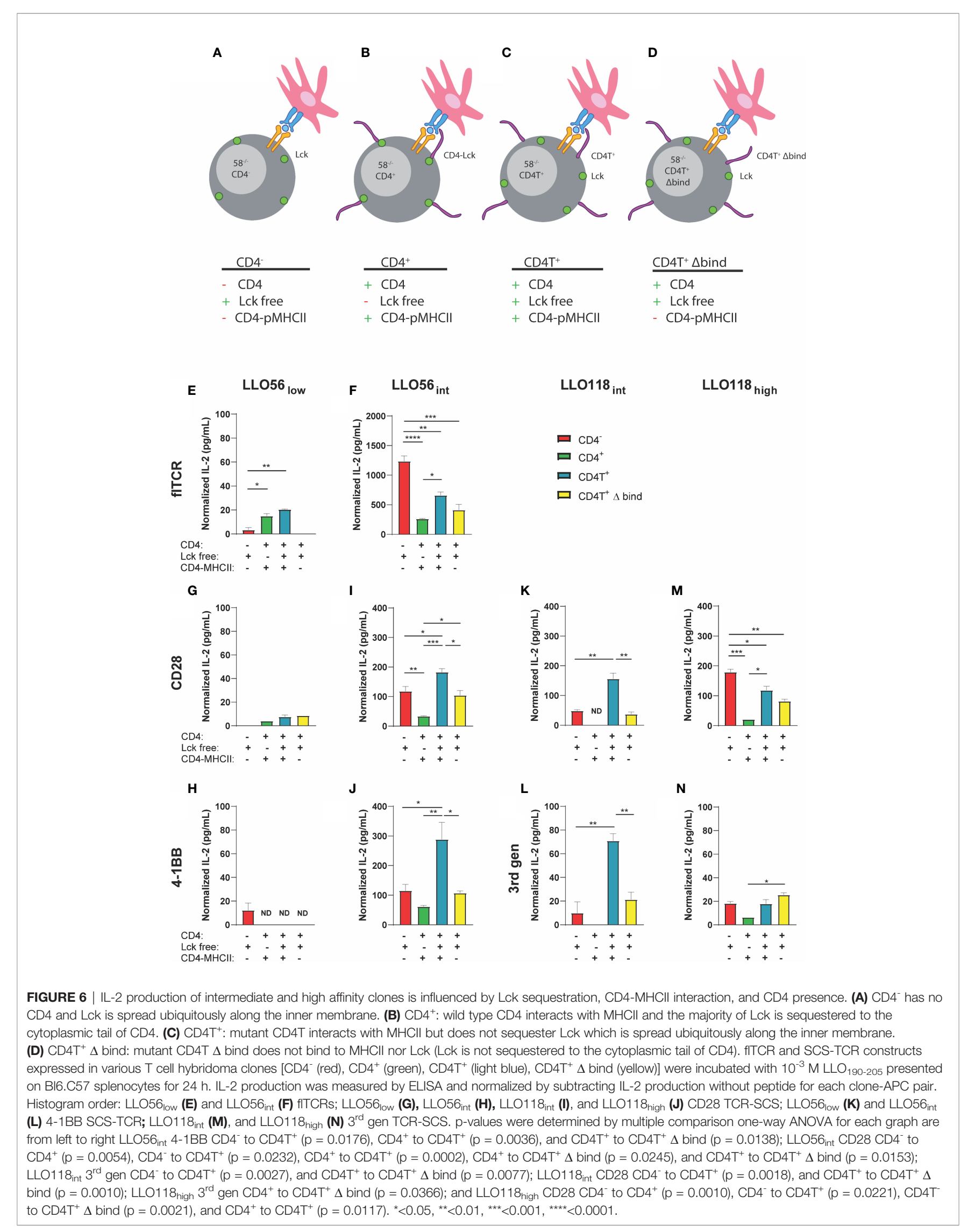


gen and LLO118 TCR SCS 4-1BB clones were dropped due to their poor performance in the first IL-2 tests. The $58^{-/-} \mathrm{CD} 4^{-} \mathrm{T}$ cell hybridoma cell line (CD4-) lack CD4, which allows Lck to interact freely with the TCR-pMHCII complex and nullifies CD4-MHCII interactions (Figure 6A). The $58^{-/-} \mathrm{CD}^{+} \mathrm{T}$ cell hybridoma cell line $\left(\mathrm{CD} 4^{+}\right)$has wild type $\mathrm{CD} 4$ which sequesters Lck to its cytoplasmic tail and binds to MHCII (Figure 6B). $58^{-/-}$ $\mathrm{CD}_{4} \mathrm{~T}^{+} \mathrm{T}$ cell hybridoma line $\left(\mathrm{CD} 4 \mathrm{~T}^{+}\right)$is truncated C-terminally (maintains amino acids 1-421) which allow Lck to colocalize but not bind to CD4 while CD4 still binds to MHCII (Figure 6C) $(60,70)$. CD4T expressed in both $\mathrm{T}$ cells and hybridomas has been documented in many sources to not bind $\operatorname{Lck}(60,70,71)$ and is suggested to produce IL-2 in a Lck-independent manner $(60,70,71)$. Previous work has also demonstrated in cells that, while CD4TAbind does not bind MHCII, it still contains the cytoplasmic tail necessary for binding Lck $(72,73)$. Finally, $58^{-/-}$ $\mathrm{CD}_{4} \mathrm{~T}^{+} \Delta$ bind $\left(\mathrm{CD}_{4} \mathrm{~T}^{+} \Delta\right.$ bind) frees Lck and is mutated to prevent CD4 binding to MHCII by altering residues $68-73$ from KGVLIR to DGDSDS (Figure 6D) (60).

$\mathrm{CD}_{4} \mathrm{~T}^{+}$and $\mathrm{CD}_{4} \mathrm{~T}^{+} \Delta$ bind constructs were retrovirally transduced into existing CD4 $\mathrm{T}$ cell hybridomas containing TCR-SCS or flTCR constructs and the clones were sorted for GFP, TCR, and CD4 expression by flow sorting. CD4 $4^{-}$hybridomas did not express CD4, and there was consistent CD4 expression between the various $\mathrm{CD} 4^{+}$clones (Supplemental Figure S8) while GFP levels varied (Supplemental Figure S9A). TCR surface expression was consistent across cell lines for most TCR constructs, except LLO56 $6_{\text {low }}$ and LLO56 $6_{\text {int }}$ CD28 clones which were most stably expressed in $\mathrm{CD}^{+}$cells $(\mathrm{p}<0.0001$ and $\mathrm{p}<$ 0.0001, respectively) (Supplemental Figure S9B). Similarly, avidity measured by tetramer was mainly consistent between clones except for LLO56 low $4-1 \mathrm{BB}$ where CD4 had higher avidity than all $\mathrm{CD} 4^{+}$clones $(\mathrm{p}=0.0014)$, and LLO118 ${ }_{\text {int }} \mathrm{CD} 28$ where $\mathrm{CD}^{+}$clone had the highest avidity $(\mathrm{p}=0.0063)$ (Supplemental Figure S9C).

As expected, LLO56 $6_{\text {low }}$ flTCR IL-2 production was promoted by the presence of CD4-MHCII interactions $\left(\mathrm{CD}^{+} \mathrm{p}=0.0105\right.$ and $\mathrm{CD}_{4} \mathrm{~T}^{+} \mathrm{p}=0.0014$ ) and the absence of CD4-MHCII interaction in the $\mathrm{CD}^{-}$and $\mathrm{CD}_{4} \mathrm{~T}^{+} \Delta$ bind abrogated LLO56 $6_{\text {low }}$ flTCR IL-2 production (Figure 6E). CD4 Lck-sequestration did not affect LLO56 $6_{\text {low }}$ flTCR IL-2 production since the $\mathrm{CD} 4^{+}$and $\mathrm{CD}_{4} \mathrm{~T}^{+}$clones responded the similarly to antigen (Figure 6E). In contrast, intermediate affinity LLO56 $6_{\text {int }}$ flTCR IL-2 production is inhibited by CD4 Lck-sequestration, as $\mathrm{CD}^{+}$produced significantly less IL-2 than $\mathrm{CD}_{4} \mathrm{~T}^{+}(\mathrm{p}=0.0162)$ (Figure 6F). However, the more striking phenotype is LLO56 ${ }_{\text {int }}$ flTCR CD4dependent inhibition, as IL-2 production is significantly reduced by the presence of CD4 in any form (Figure 6F). CD4- ${ }^{-}$LO $56_{\text {int }}$ flTCR cells produced significantly more IL-2 than any clone expressing CD4 $\left(\mathrm{CD} 4^{+} \mathrm{p}<0.0001, \mathrm{CD} 4 \mathrm{~T}^{+} \mathrm{p}=0.0019\right.$, and $\mathrm{CD}_{4} \mathrm{~T}^{+} \Delta$ bind $\mathrm{p}=0.0002$ ) (Figure $6 \mathrm{~F}$ ). Furthermore, CD4MHCII interaction was not a significant contributor to intermediate affinity flTCR IL-2 production as there was no significant change in IL-2 production between the $\mathrm{CD}_{4} \mathrm{~T}^{+}$and $\mathrm{CD} \mathrm{T}^{+} \Delta$ bind clones (Figure 6F).

Low affinity TCR-SCS clones LLO56 $6_{\text {low }}$ CD28 (Figure 6G) and LLO56 $6_{\text {low }} 4$-1BB (Figure 6 $\mathbf{H}$ ) were low IL-2 producers and the role of CD4 was conflicting as all CD4 iterations inhibited IL2 production for 4-1BB but promoted IL-2 production for CD28 whether or not CD4 binds to MHCII. It was also difficult to draw conclusions about Lck-sequestration for low affinity TCR-SCS constructs due to low levels of IL2 production. Intermediate TCR-SCS clones LLO56 int $_{\text {CD28 (Figure 6I), LLO56 }}$ int $4-1 \mathrm{BB}$ (Figure 6J), LLO118 $8_{\text {int }}$ CD28 (Figure 6K), and LLO118 $8_{\text {int }}$ $3^{\text {rd }}$ gen (Figure 6L) had a unique ubiquitous phenotype comparable to the phenotype described for intermediate affinity flTCR clones. IL-2 production was most reduced when CD4 sequestered Lck in the $\mathrm{CD}^{+}$clones (Figures 6I-L). However, intermediate TCR-SCS CD4T ${ }^{+}$constructs produced the most IL-2, indicating unrestricted Lck promotes the greatest $\mathrm{T}$ cell activation (Figures $\mathbf{6 I}-\mathbf{L}$ ). $\mathrm{CD}_{4} \mathrm{~T}^{+} \Delta$ bind compared to $\mathrm{CD}_{4} \mathrm{~T}^{+}$significantly reduced intermediate TCR-SCS construct IL-2 production to $\mathrm{CD}^{-}$levels suggesting that CD4-MHCII binding supports IL-2 production for intermediate TCR-SCS affinity (Figures 6I-L). Noticeably, high affinity LLO118 TCRSCSs followed the same inhibition patterns seen for LLO56 $6_{\text {int }}$ flTCR where inhibition by Lck sequestration and CD4 presence was not significantly affected by MHCII-CD4 binding (Figures $\mathbf{6 M}, \mathbf{N}$ ). Taken together, these data indicate that flTCRs and TCR-SCS have independent affinity thresholds for the inhibitory effects of Lck-sequestration and CD4-dependent inhibition, and the activation promoting effects of CD4-MHCII interactions (summarized in Table 3). Thus, IL-2 inhibition is affected by CD4-Lck sequestration, CD4-pMHCII interaction, and by a CD4-dependent mechanism in an affinity- and formatdependent manner.

TABLE 3 | Summary of Figures 6

\begin{tabular}{|c|c|c|c|c|c|c|c|c|c|c|}
\hline & & \multicolumn{3}{|c|}{ low } & \multicolumn{3}{|c|}{ int } & \multicolumn{3}{|c|}{ high } \\
\hline \multirow[t]{2}{*}{ LLO56 } & fITCR & NA & NA & + & - & + & NA & & & \\
\hline & CD28 & + & NA & NA & NA & + & + & & & \\
\hline \multirow[t]{2}{*}{ LLO118 } & CD28 & & & & NA & + & + & - & + & NA \\
\hline & 3rd gen & & & & NA & + & + & NA & + & NA \\
\hline
\end{tabular}

IL-2 production data interpretation broken down into base TCR (LLO56 or LLO118), construct, and TCR-pMHCIl affinity. "-" indicates that the condition inhibits or does not promote IL-2 production, "NA" indicates that effects on IL-2 production were "not appreciable", and "+" indicates that the condition promotes or least does not inhibit IL-2 production. Bolded interior boxes highlight the phenotype shared by intermediate affinity fITCR and high affinity TCR-SCS clones. 


\section{DISCUSSION}

Here, we engineered and characterized a panel of MHCIIspecific TCRs with increasing pMHC affinity in order to interrogate the relationships between TCR format, TCRpMHCII affinity, and the coreceptor CD4 on $\mathrm{CD}^{+} \mathrm{T}$ cell activation. In addition to the generation of a high affinity MHCII-dependent TCR model, we identify a CD4-dependent phenotype potentially relevant for cancer-immunotherapeutic development and show that high affinity flTCRs outperform TCR-SCS formats, that TCR-SCS format effects on T cell activation are more dependent on the TCR than the TCR-SCS format, and that CD4 can inhibit both flTCR and TCR-SCS activation in an Lck dependent and independent fashion. This study utilized $58^{-/-} \mathrm{T}$ cell hybridomas as a proxy for $\mathrm{T}$ cell activation activity. While not as physiologically relevant as using primary $\mathrm{T}$ cells, this system has the advantage of enabling the survey of $\mathrm{T}$ cell activation characteristics for multiple constructs as we have done here and has been frequently used as a springboard for further exploration of high affinity TCRs in primary T cells $(47,65,74,75)$. The contributions of these factors were assessed using IL-2 production, which is a proxy, but not a complete indication of $\mathrm{T}$ cell activation. flTCRs produced more IL-2 than all TCR-SCS constructs at each affinity level and IL-2 production generally increased with rising TCR affinity for all constructs. In low affinity TCRs, CD4 enhanced IL-2 production for both flTCR and TCR-SCS formats. For intermediate or high affinity TCR clones, IL-2 production was abrogated by CD4-Lck sequestration and an unknown CD4-dependent mechanism. These effects, activation promotion by increased affinity and CD4-MHCII, or activation suppression by Lck-sequestration and CD4 itself, had unique affinity thresholds that are dependent on construct type (flTCR or TCR-SCS). Lck sequestration affected activation for all intermediate and high affinity constructs, while CD4-MHCII ceased to promote activation and CD4-dependent inhibition repressed IL-2 production at unique affinity thresholds for flTCR constructs (intermediate affinity) and TCR-SCS constructs (high affinity). It is possible that Lck sequestration or the constructs themselves, have unique and important effects on other activation markers (such as the early activation markers CD25, pLCk, pCD3 $\zeta$, pERK, CD69), inhibitory markers (such as PD1 and LAG3), tonic signaling, $\mathrm{T}$ cell proliferation and effector function, which should be investigated in primary $\mathrm{T}$ cells in the future.

The balance of free unbound Lck and coreceptor-bound Lck affects $\mathrm{T}$ cell developmental fate, and $\mathrm{T}$ cell responsiveness in the periphery. Following colocalization to the TCR, CD4 signals via Lck bound to its cytoplasmic tail $(68,69)$. Lck phosphorylates immune-receptor tyrosine-based activating motifs (ITAMs) of the CD3 subunits of the TCR complex, which then initiates other early signaling machinery of the T cell $(69,76,77)$. Bound and unbound Lck signal independently and can alter $\mathrm{T}$ cell development and function $(78,79)$. During thymic selection, the intracellular coreceptor-bound or unbound state of Lck determines whether $\alpha \beta$ TCRs are MHC-restricted or independent (78). Lck association with coreceptor proteins determines MHC restriction (78), and coreceptor-Lck binding stoichiometry is the limiting factor for signaling during selection (80). In particular, CD8, which binds Lck more preferentially than CD4, has a greater effect on TCR selection and increases $\mathrm{CD}^{+} \mathrm{T}$ cell reactivity to low affinity and self-reactive antigen compared to $\mathrm{CD} 4^{+} \mathrm{T}$ cells (80). In both mature $\mathrm{CD} 8^{+} \mathrm{T}$ cells and $\mathrm{T}$ cell hybridomas, free Lck has higher mobility, more activating Y394 phosphorylation, higher kinase activity, and mediated higher $\mathrm{T}$ cell activation compared to coreceptor-bound Lck (81). Additionally, during activation, TCR-CD3 is first phosphorylated by unbound-Lck followed by MHC-dependent CD3-CD8 interaction and the less activated coreceptor-bound Lck (82-84). CD4-bound Lck activation may be reliant on a mechanism distinct from CD4-free Lck activation, which is likely mediated by tyrosine-protein kinase Fyn and may obscure mechanism comparison $(37,85,86)$. Additionally, it is also possible that CD4 may function differently in $\mathrm{T}$ cells expressing native TCRs or CAR cytoplasmic domains. However, despite these potential complications, CD4-Lck-dependent inhibition could occur in two fashions. First, optimal TCR affinity-mediated signaling is dependent on fine-tuning the intensity and duration of the Lck phosphorylation cascade and high affinity TCRs may have early intense Lck phosphorylation resulting in acute transient activation (87). Conversely, if CD4 is not recruited to the TCR, it could sequester Lck away from the activation complex, which prevents the activation phosphorylation cascade thereby attenuating $\mathrm{T}$ cell activation (49). The first option suggests that all high-affinity TCR signaling would be attenuated regardless of whether Lck was interacting with CD4; however, IL-2 output reduction in the presence of CD4-Lck sequestration is clearly demonstrated by our intermediate and high affinity CD4+ $\mathrm{T}$ cell hybridoma clones. It is also possible that with an increase in affinity and the subsequent decrease in off-rate or increase in half-life, CD4Lck fails to cycle through the TCR-pMHC synapse, thereby decreasing CD3 phosphorylation and thus downstream activation. Signaling activation is affected by both TCRpMHCII dwell time and CD4-Lck interactions (70, 88, 89). CD4 increases TCR signaling on low-affinity pMHCII by increasing TCR-CD3 dwell time (39). CD4 dwell time on pMHCII is proportional, yet faster, to TCR dwell time, suggesting that TCR:pMHCII interaction kinetics would directly affect the duration that CD4 molecules cycle through the immunological synapse in a processive-like manner (88). Additionally, compared to coreceptor-bound Lck, CD4-free Lck is phosphorylated more at its Y394 activation site, with higher kinase activity and mobility (81); thus, it may be that if CD4-free Lck is prevented from interacting with the immunological synapse, activation may be reduced. TCR-pMHCII interactions are highly ordered and uniform, increasing the likelihood that the spatial relationship between Lck and the ITAMs of the TCR-SCS or flTCRs are consistent. Thus, kinetic factors, such as TCR-pMHCII affinity would greatly influence the stability of the macrocomplex and consequently the duration of Lck interactions with the ITAMs $(39,90)$. These kinetics alone could explain the drop in activation observed for our 
high-affinity, slow off-rate TCR clones. To support this idea, CD8 also acts as a dominant negative inhibitor for ligands that do not recruit fresh CD8 to the TCR-CD3 complex (49).

Previous research suggests that CD4 can send an inhibitory signal independent of Lck via post activation antibody-mediated ligation, which attenuates IL-2 production and ongoing activated $\mathrm{T}$ cell response (91). This response was also observed in a clonal variant expressing a form of CD4 unable to associate with Lck, suggesting that CD4 has independent inhibitory or regulatory function (91). Furthermore, CD4-mediated inhibition has also been observed during CD4-MHCII interactions leading to a decrease in IL-2 mRNA (91). While we did not seek the source for our Lck-independent CD4 inhibition nor acquire IL-2 mRNA levels, we noted that there was an affinity threshold for this behavior that was independent of MHC interaction, and therefore may be a unique mechanism to that reported in Chervin et al. (49). The affinity threshold for this Lckindependent CD4 inhibition was lower for flTCR (intermediate affinity) than TCR-SCS (high affinity). This may be due to the signaling power of each construct: flTCR-CD3 complexes have 10 ITAMs with 20 tyrosine residues available for phosphorylation, whereas TCR-SCS domains have only 3 ITAMs and 6 tyrosine residues $(47,92,93)$. The increased availability of ITAMs per activated Lck may also explain why LLO56 $6_{\text {int }}$ flTCR experienced less IL-2 production inhibition in the presence of CD4-more signal per Lck molecule despite CD4-Lck movement restriction. Whether SCS-TCRs function as dimers is unclear and remains a topic of study $(67,94,95)$. It is also curious that the CD4-MHCII interaction supports activation in intermediate affinity TCR-SCS clones, suggesting that while CD4 may not contribute to the overall affinity of TCR-SCS constructs, it may stabilize the interaction between TCRpMHCII or provide an additional Lck-independent activation signal. The increased interaction stability is more likely as high affinity TCR-SCS IL-2 production is not significantly improved when CD4 interacts with MHCII, suggesting high affinity constructs likely have stable interactions independent of CD4 contributions. Taken together this data suggests an affinity threshold where, up to a point, increased time for CD4-MHCII interactions improves TCR-dependent signaling when it is not Lck-limited, but after a certain affinity point, increased dwell time slows TCR-dependent signaling and positive benefits of CD4-MHCII interactions become redundant.

In addition to the stability challenges presented by scTCR format, the TCR-SCS intracellular format also affected the stability of each TCR. TCR-SCS CD28 format was more stably expressed than other TCR-SCS or flTCR formats, and as noted in other studies, the enhanced surface expression of TCR-SCS CD28 formats via increased stability may explain their improved avidity and $\mathrm{T}$ cell activation (96-98). However, it is difficult to ascertain whether the increased IL-2 production of TCR-SCS CD28 is due to enhanced stable surface expression or the innate characteristics of CD28-intracellular signaling domains. As observed in numerous antibody-based CAR studies comparing CD28 domains to 4-1BB domains, intracellular signaling domains differentially impact multifactorial $\mathrm{T}$ cell response characteristics, including cytokine production (99). For example, CD28-CAR constructs, which can directly bind Lck, are well known for their Lck-binding-dependent enhanced IL-2 production, increased tonic signaling, and subsequent $\mathrm{T}$ cell exhaustion compared to 4-1BB CARs (100103). Thus, the observed increase in IL-2 production for TCRSCS CD28 constructs may be attributable to the innate characteristics of CD28-intracellular signaling domains rather than increased stable surface expression. As CD28-CARs phosphorylate CD3 more quickly yet do not exceed the levels of CD3 phosphorylation exhibited by 4-1BB CARs, this may be due to signaling intensity (101). Additionally, because CD28 recruits Lck to lipid rafts where it associates with CD4, CD28 may be better able to recruit Lck $(104,105)$. While TCR-SCS $3^{\text {rd }}$ generation constructs had mixed activation success and overall reduced cytokine production compared to TCR-SCS CD28 constructs, this may be attributable to $3^{\text {rd }}$ generation CAR T cells improved expansion and persistence and may mimic some characteristics of 4-1BB CAR T cells, like reduced cytokine production $(106,107)$. Our TCR-SCS CD28 constructs demonstrated similarities to antibody-based CD28 CARs, including enhanced tonic signaling in some clones, suggesting that TCR SCS CD28 may also have increased T cell exhaustion. However, unlike CD28 CARs, CD4 expression ameliorated tonic signaling in our TCR-SCS constructs. It will be important to examine the role of CD4 in primary $\mathrm{T}$ cells to determine if CD4 prevents exhaustion in clones expressing TCRSCS CD28 constructs.

$\mathrm{CD}^{+} \mathrm{T}$ cells are promising newcomers to immunotherapy. $\mathrm{CD}^{+}{ }^{+}$TCRs convey exquisite target specificity and direct robust immune responses through indirect mechanisms that avoid tumor antigen escape. While much development and thought has been devoted to the activation benefits and off-target effects of increased TCR-pMHC affinity, especially for $\mathrm{CD}^{+}$TCRs, further TCR-therapeutic development should give consideration to the unique affinity thresholds of TCR-SCS and flTCR formats and the potential inhibitory effects of CD4.

\section{DATA AVAILABILITY STATEMENT}

The original contributions presented in the study are included in the article/Supplementary Material. Further inquiries can be directed to the corresponding author.

\section{ETHICS STATEMENT}

The animal study was reviewed and approved by Brigham Young University's Institutional Animal Care and Use Committee (IACUC protocol \#18-0708).

\section{AUTHOR CONTRIBUTIONS}

DJ conceived the experiments. DJ, WM, SM, JF, JH, and TO conducted the experiments. KW and $\mathrm{KC}$ provided experimental advice. SP cloned the initial LLO118 and LLO56 
constructs in the yeast display constructs and permitted use of previously published data. DJ analyzed data and wrote the manuscript. All authors reviewed the manuscript. All authors contributed to the article and approved the submitted version.

\section{FUNDING}

This work was supported by a R15 grant to KW (R0102063) from the National Institutes of Health, Simmons Center for Cancer Research Summer Fellowships and Graduate Student Fellowship grants at Brigham Young University to DJ.

\section{ACKNOWLEDGMENTS}

We thank National Institutes of Health Tetramer Core Facility at Emory University for providing the MHC tetramers. We thank Dr. Claudia Tellez Freitas for her help with initial cell culture training and advice. We thank Dr. Dan Harris and Dr. David Kranz (University of Illinois Urbana-Champaign) for Platinum Ecotrophic, $58^{-/-}$and $58^{-/-} \mathrm{CD}^{+}$cell hybridoma lines, TCR-SCS constructs and flTCR expression advice. We also thank Dr. Michael Kunz (University of Arizona) for $\mathrm{CD}_{4} \mathrm{~T}^{+}$and $\mathrm{CD}_{4} \mathrm{~T}^{+}$ $\Delta$ bind constructs and for his excellent critical review of the manuscript.

\section{SUPPLEMENTARY MATERIAL}

The Supplementary Material for this article can be found online at: https:/www.frontiersin.org/articles/10.3389/fimmu.2020.561889/ full\#supplementary-material

SUPPLEMENTARY FIGURE 1 | LLO118 and LLO56 single-chain TCRS stabilizing mutations. Wild type templates (LLO118 $8_{W T}$ and LLO56 $W_{T T}$ ) compared to stabilized single-chain TCR (scTCR) templates (LLO118 $8_{\text {low }}$ and LLO56 Iow). The original LLO56 $6_{W T}$ ScTCR template included mutations of the amino acid K42 $3 \mathrm{G}$, $\mathrm{H} 36 \alpha \mathrm{Y}$ and $\mathrm{S} 74 \alpha \mathrm{T}$ (highlighted gray) known to enhance surface display levels in related TCRs (108). Stability mutations selected by random mutagenesis and directed evolution are marked in red. Boxed amino acids show joint LLO118 $8_{\text {low }}$ and LLO56 $_{\text {low }}$ selection (K42ßG and T933A), and mutations in another known stability hotspot ( $L 45 \alpha \mathrm{l}$ and I49 $\alpha \mathrm{M})$ are unmarked. LLO118 $8_{\text {low }}$ independently selected

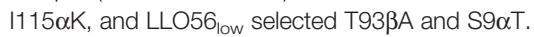

SUPPLEMENTARY FIGURE 2 | Protein sequence map for 4-1BB SCS-TCR formats for (A) LLO56 low and LLO56 int, and (B) LLO118 low, LLO118 $_{\text {int }}$, and

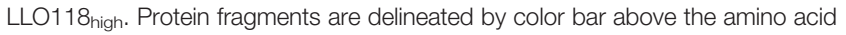
sequence. Stability mutations (highlighted grey or red font) are marked as indicated in Supplemental Figure 1. CDR3 $\beta$ mutations for additional clones are listed below the sequence map.

SUPPLEMENTARY FIGURE 3 | Protein sequence map for CD28 SCS-TCR formats for (A) LLO56 low and LLO56 $6_{\text {int }}$, and (B) LLO118 low, LLO118 $_{\text {int }}$, and

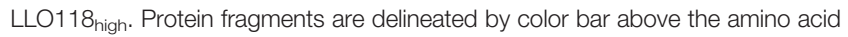
sequence. Stability mutations (highlighted grey or red font) are marked as indicated in Supplemental Figure 1. CDR3 $\beta$ mutations for additional clones are listed below the sequence map.

SUPPLEMENTARY FIGURE 4 | Protein sequence map for $3^{\text {rd }}$ gen SCS-TCR formats for (A) LLO56 low and LLO56 int, and (B) LLO118 $8_{\text {low, }}$ LLO118 $8_{\text {int }}$, and LLO118 $8_{\text {high. }}$ Protein fragments are delineated by color bar above the amino acid sequence. Stability mutations (highlighted grey or red font) are marked as indicated in Supplemental Figure 1. CDR3 $\beta$ mutations for additional clones are listed below the sequence map.

SUPPLEMENTARY FIGURE 5 | Protein sequence map for fITCR formats for LLO56 $_{\text {low }}$ and LLO56 $6_{\text {int }}$. Protein fragments are delineated by color bar above the amino acid sequence. Stability mutations were removed for fITCR constructs. CDR3 $\beta$ mutations for additional clones are listed below the sequence map.

SUPPLEMENTARY FIGURE 6 | GFP expression levels for $\mathrm{CD}^{-}$and $\mathrm{CD} 4^{+}$ clones. GFP MFI is significantly different for most SCTCR and fITCR constructs between $\mathrm{CD} 4^{-}$and $\mathrm{CD} 4^{+}$pairs including LLO56 low $_{\text {lo }} 4$-1BB $(p<0.0001)$, LLO56 $6_{\text {int }} 4-$ $1 \mathrm{BB}(\mathrm{p}<0.0001)$, LLO56 $_{\text {low }}$ CD28 $(p=0.0016)$, LLO56 $_{\text {int }}$ CD28 $(p=0.0001)$, LLO56 $_{\text {low }} 3^{\text {rd }}$ gen $(p=0.0054)$, LLO56 $6_{\text {int }} 3^{\text {rd }}$ gen $(p<0.0001)$, LLO56 $6_{\text {low }}$ fITCR $(p=$ $0.0058)$, LLO118 $8_{\text {low }} 4-1 B B(p<0.0001)$, LLO118 $8_{\text {int }} 4-1 \mathrm{BB}(p<0.0001)$, LLO118 $8_{\text {low }}$ CD28 $(p<0.0001)$, LLO118 $8_{\text {int }}$ CD28 $(p=0.0012)$, LLO118 int $3^{\text {rd }}$ gen $(p<0.0001)$, and LLO118 $8_{\text {high }} 3^{\text {rd }}$ gen $(p<0.0001)$.

SUPPLEMENTARY FIGURE 7 | Comparison of IL-2 production at $10^{-3} \mathrm{M}$ peptide stimulation. Analysis of levels of IL-2 production from Figure 5 at $10^{-3} \mathrm{M}$ peptide stimulation. IL-2 production between 58-/-CD4- affinity clones was significantly different for LLO56low and LLO56int 4-1BB ( $p=0.0211)$, LLO56low and LLO56int CD28 ( $p=0.0039)$ and LLO56low and LLO56int fITCR ( $p=0.0033)$, LLO118low and LLO118int 3rd gen ( $p=0.0006)$, LLO118low and LLO118high 3rd gen $(p=0.0070)$, LLO118low and LLO118int 4-1BB $(p=0.0441)$, LLO118low and LLO118high 4-1BB $(p=0.0115)$, LLO118low and LLO118int CD28 $(p=0.0489)$, LLO118low and LLO118high CD28 ( $<<0.0001)$, and LLO118int and LLO118high CD28 $(p<0.0001)$.

SUPPLEMENTARY FIGURE 8 | CD4 is not expressed in CD4- SCS-TCR, fITCR and base $58^{-/-}$hybridoma cell lines. Twenty-five thousand cells were stained with antibody mix for 10 mins. 10,000 events collected via flow cytometry. (A) Isotype stain LLO56 high $_{\text {CD28, LLO56 }}$ high fITCR, and base $58^{-/-}$T cell hybridoma lines not expressing TCRs were stained with antibody mix [anti-V $32 \mathrm{PE}$, anti-V $\alpha$ APC, and anti-F4/80 PE Cy7 (rat IgG2, Fisher Scientific)]. Histograms display anti-F4/80 PECy7: Cells only (grey), $\mathrm{CD}^{-}$clones (green), and all $\mathrm{CD}^{+}$clones (red) including $\mathrm{CD}^{+}, \mathrm{CD} \mathrm{T}^{+}$and $\mathrm{CD} 4 \mathrm{~T}^{+} \Delta$ bind. (B) CD4 stain of LLO56 high $_{\text {CD28, LLO56 }}$ high fITCR, and base $58^{-/-} \mathrm{T}$ cell hybridoma lines not expressing TCRs were stained with antibody mix [anti-VB2 PE, anti-V $\alpha$ APC, and anti-CD4 PE Cy7 (rat lgG2, Fisher Scientific)]. Histograms display anti-F4/80 PE-Cy7: Cells only (grey), CD4- clones (blue), and all $\mathrm{CD}^{+}$clones (red) including $\mathrm{CD}^{+}, \mathrm{CD} 4 \mathrm{~T}^{+}$and $\mathrm{CD} 4 \mathrm{~T}^{+} \Delta$ bind. (C) Comparison of isotype stain (green) and CD4 stain (blue) for CD4:

SUPPLEMENTARY FIGURE 9 | GFP expression levels for SCS constructs (A) GFP expression by construct in order of $58^{-1-} \mathrm{CD} 4^{-}, 58^{-/} \mathrm{CD} 4^{+}, 58^{-1-} \mathrm{CD} \mathrm{T}^{+}, 58^{-1}$ $\mathrm{CD}_{4} \mathrm{~T}^{+} \Delta$ bind $\mathrm{T}$ cell hybridomas. Both $\mathrm{CD} 4 \mathrm{~T}^{+}$and $\mathrm{CD} 4 \mathrm{~T}^{+} \Delta \mathrm{bind}$ and $\mathrm{TCR}$ s were inserted into the cell lines via the vector pMIGII which uses GFP as a reporter gene. Thus, the GFP expression for all $\mathrm{CD} 4 \mathrm{~T}^{+}$and $\mathrm{CD} 4 \mathrm{~T}^{+} \Delta$ bind cell lines are significantly higher than CD4 ${ }^{-}$and CD4 ${ }^{+}$cell lines. LLO56 low $_{\text {(pink colors), LLO56 }}$ int (red colors), LLO118 $8_{\text {int }}$ (light blue colors), LLO118 $8_{\text {high }}$ (dark blue colors). Hatched lines indicate CD4-MHC interactions. LLO56 low 4-1BB ( $p<0.0001)$, LLO56 $6_{\text {int }} 4-1 \mathrm{BB}(p<0.0001)$, LLO56 low CD28 $(p<0.0001)$, LLO56 int CD28 $(p<0.0001)$, LLO118 $8_{\text {int }} 3^{\text {rd }}$ gen $(p<0.0001)$, LLO118 high $3^{\text {rd }}$ gen $(p<0.0001)$, LLO118 int $_{\text {CD28 }}(p<0.0001)$, and LLO118 high $_{\text {CD28 }}$ $(p<0.0001)$. (B) Stable expression of V 32 by construct. LLO56 low $C D 28(p<0.0001)$ and LLO56 $6_{\text {int }} \mathrm{CD} 28(p<0.0001)$ (C) To ascertain whether avidity was maintained within each TCR-construct despite CD4 variations, each cell line was tested at sub-saturating tetramer concentrations: LLO56 low $\left(10^{-8} \mathrm{M}\right)$, LLO56 $_{\text {int }}\left(5 \times 10^{-10} \mathrm{M}\right)$, LLO11 $_{\text {int }}\left(10^{-9} \mathrm{M}\right)$, and LL0118 $8_{\text {high }}\left(5 \times 10^{-10} \mathrm{M}\right)$. Colors and order as found in (B). LLO118 $8_{\text {int }}$ CD28 ( $p=$ 0.033). Groups analyzed for differences with one-way ANOVA.

SUPPLEMENTARY TABLE 1 | Summary of T cell responses of LLO56 and LLO118 to antigen adapted from Persaud et al. LLO118 and LLO56 differentially respond to activation by peptide LLO $190-205$. LLO118 and LLO56 have similar proliferation responses to LLO $190-205$ in vitro, but in vivo LLO118 has a more robust primary response while LLO56 has a more robust secondary response. LLO56 produces more IL-2 in vitro and undergoes higher rates of apoptosis during the primary response than LLO118. Surface plasma resonance measurements of LLO56 and LLO118 dissociation constants are 27.4 and $28.3 \mu \mathrm{M}$, respectively $(41,42)$. 


\section{REFERENCES}

1. Borst J, Ahrends T, Babala N, Melief CJM, Kastenmuller W. CD4(+) T cell help in cancer immunology and immunotherapy. Nat Rev Immunol (2018) 18:635-47. doi: 10.1038/s41577-018-0044-0

2. Matsuzaki J, Tsuji T, Luescher IF, Shiku H, Mineno J, Okamoto S, et al. Direct tumor recognition by a human CD4(+) T-cell subset potently mediates tumor growth inhibition and orchestrates anti-tumor immune responses. Sci Rep (2015) 5:14896. doi: 10.1038/srep14896

3. Quezada SA, Simpson TR, Peggs KS, Merghoub T, Vider J, Fan X, et al. Tumor-reactive CD4(+) T cells develop cytotoxic activity and eradicate large established melanoma after transfer into lymphopenic hosts. J Exp Med (2010) 207:637-50. doi: 10.1084/jem.20091918

4. Xie Y, Akpinarli A, Maris C, Hipkiss EL, Lane M, Kwon EK, et al. Naive tumor-specific CD4(+) T cells differentiated in vivo eradicate established melanoma. J Exp Med (2010) 207:651-67. doi: 10.1084/jem.20091921

5. Brunsvig PF, Aamdal S, Gjertsen MK, Kvalheim G, Markowski-Grimsrud CJ, Sve I, et al. Telomerase peptide vaccination: a phase I/II study in patients with non-small cell lung cancer. Cancer Immunol Immunother (2006) 55:1553-64. doi: 10.1007/s00262-006-0145-7

6. Brunsvig PF, Kyte JA, Kersten C, Sundstrom S, Moller M, Nyakas M, et al. Telomerase peptide vaccination in NSCLC: a phase II trial in stage III patients vaccinated after chemoradiotherapy and an 8-year update on a phase I/II trial. Clin Cancer Res (2011) 17:6847-57. doi: 10.1158/10780432.CCR-11-1385

7. Kyte JA, Gaudernack G, Dueland S, Trachsel S, Julsrud L, Aamdal S. Telomerase peptide vaccination combined with temozolomide: a clinical trial in stage IV melanoma patients. Clin Cancer Res (2011) 17:4568-80. doi: 10.1158/1078-0432.CCR-11-0184

8. Suso EM, Dueland S, Rasmussen AM, Vetrhus T, Aamdal S, Kvalheim G, et al. hTERT mRNA dendritic cell vaccination: complete response in a pancreatic cancer patient associated with response against several hTERT epitopes. Cancer Immunol Immunother (2011) 60:809-18. doi: 10.1007/ s00262-011-0991-9

9. Garrido F, Cabrera T, Aptsiauri N. "Hard" and "soft" lesions underlying the HLA class I alterations in cancer cells: implications for immunotherapy. Int J Cancer (2010) 127:249-56. doi: 10.1002/ijc.25270

10. Lu YC, Parker LL, Lu T, Zheng Z, Toomey MA, White DE, et al. Treatment of Patients With Metastatic Cancer Using a Major Histocompatibility Complex Class II-Restricted T-Cell Receptor Targeting the Cancer Germline Antigen MAGE-A3. J Clin Oncol (2017) 35:3322-9. doi: 10.1200/JCO.2017.74.5463

11. Inderberg EM, Wälchli S. Long-term surviving cancer patients as a source of therapeutic TCR. Cancer Immunol Immunother (2020) 69(5):859-65. doi: 10.1007/s00262-019-02468-9

12. van der Merwe PA, Davis SJ. Molecular interactions mediating T cell antigen recognition. Annu Rev Immunol (2003) 21:659-84. doi: 10.1146/ annurev.immunol.21.120601.141036

13. Corse E, Gottschalk RA, Allison JP. Strength of TCR-peptide/MHC interactions and in vivo T cell responses. J Immunol (Baltimore Md 1950) (2011) 186:5039-45. doi: 10.4049/jimmunol.1003650

14. Holler PD, Kranz DM. Quantitative analysis of the contribution of TCR/ pepMHC affinity and CD8 to T cell activation. Immunity (2003) 18:255-64. doi: 10.1016/S1074-7613(03)00019-0

15. Krogsgaard M, Prado N, Adams EJ, He XL, Chow DC, Wilson DB, et al. Evidence that structural rearrangements and/or flexibility during TCR binding can contribute to T cell activation. Mol Cell (2003) 12:1367-78. doi: 10.1016/S1097-2765(03)00474-X

16. Laugel B, van den Berg HA, Gostick E, Cole DK, Wooldridge L, Boulter J, et al, et al. Different $\mathrm{T}$ cell receptor affinity thresholds and CD8 coreceptor dependence govern cytotoxic T lymphocyte activation and tetramer binding properties. J Biol Chem (2007) 282:23799-810. doi: 10.1074/jbc.M700976200

17. Schmid DA, Irving MB, Posevitz V, Hebeisen M, Posevitz-Fejfar A, Sarria JC, et al. Evidence for a TCR affinity threshold delimiting maximal CD8 T cell function. I Immunol (Baltimore Md 1950) (2010) 184:4936-46. doi: 10.4049/jimmunol.1000173

18. Tian S, Maile R, Collins EJ, Frelinger JA. CD8+ T cell activation is governed by TCR-peptide/MHC affinity, not dissociation rate. J Immunol (Baltimore Md 1950) (2007) 179:2952-60. doi: 10.4049/jimmunol.179.5.2952
19. Zehn D, Lee SY, Bevan MJ. Complete but curtailed T-cell response to very low-affinity antigen. Nature (2009) 458:211-4. doi: 10.1038/nature07657

20. Aleksic M, Liddy N, Molloy PE, Pumphrey N, Vuidepot A, Chang KM, et al. Different affinity windows for virus and cancer-specific T-cell receptors: implications for therapeutic strategies. Eur J Immunol (2012) 42:3174-9. doi: 10.1002/eji.201242606

21. Starr TK, Jameson SC, Hogquist KA. Positive and negative selection of T cells. Annu Rev Immunol (2003) 21:139-76. doi: 10.1146/annurev.immunol.21.120601.141107

22. Mandl JN, Monteiro JP, Vrisekoop N, Germain RN. T Cell Positive Selection Uses Self-Ligand Binding Strength to Optimize Repertoire Recognition of Foreign Antigens. Immunity (2013) 38:263-74. doi: 10.1016/j.immuni. 2012.09.011

23. Varela-Rohena A, Molloy PE, Dunn SM, Li Y, Suhoski MM, Carroll RG, et al. Control of HIV-1 immune escape by CD8 T cells expressing enhanced T-cell receptor. Nat Med (2008) 14:1390-5. doi: 10.1038/nm.1779

24. Corse E, Gottschalk RA, Krogsgaard M, Allison JP. Attenuated T cell responses to a high-potency ligand in vivo. PloS Biol (2010) 8(9):1-12. doi: 10.1371/journal.pbio.1000481

25. Irving M, Zoete V, Hebeisen M, Schmid D, Baumgartner P, Guillaume P, et al, et al. Interplay between $\mathrm{T}$ cell receptor binding kinetics and the level of cognate peptide presented by major histocompatibility complexes governs CD8+ T cell responsiveness. J Biol Chem (2012) 287:23068-78. doi: 10.1074/ jbc.M112.357673

26. McMahan RH, McWilliams JA, Jordan KR, Dow SW, Wilson DB, Slansky JE. Relating TCR-peptide-MHC affinity to immunogenicity for the design of tumor vaccines. J Clin Invest (2006) 116:2543-51. doi: 10.1172/JCI26936

27. Persaud SP, Donermeyer DL, Weber KS, Kranz DM, Allen PM. High-affinity $\mathrm{T}$ cell receptor differentiates cognate peptide-MHC and altered peptide ligands with distinct kinetics and thermodynamics. Mol Immunol (2010) 47:1793-801. doi: 10.1016/j.molimm.2010.02.013

28. Donermeyer DL, Weber KS, Kranz DM, Allen PM. The study of high-affinity TCRs reveals duality in T cell recognition of antigen: Specificity and degeneracy. J Immunol (2006) 177:6911-9. doi: 10.4049/jimmunol.177.10.6911

29. Weber KS, Donermeyer DL, Allen PM, Kranz DM. Class II-restricted T cell receptor engineered in vitro for higher affinity retains peptide specificity and function. Proc Natl Acad Sci USA (2005) 102:19033-8. doi: 10.1073/ pnas.0507554102

30. Zhong S, Malecek K, Johnson LA, Yu Z, Vega-Saenz de Miera E, Darvishian F, et al. T-cell receptor affinity and avidity defines antitumor response and autoimmunity in T-cell immunotherapy. Proc Natl Acad Sci USA (2013) 110:6973-8. doi: 10.1073/pnas.1221609110

31. Hebeisen M, Baitsch L, Presotto D, Baumgaertner P, Romero P, Michielin O, et al. SHP-1 phosphatase activity counteracts increased $\mathrm{T}$ cell receptor affinity. J Clin Invest (2013) 123:1044-56. doi: 10.1172/JCI65325

32. Kalergis AM, Boucheron N, Doucey MA, Palmieri E, Goyarts EC, Vegh Z, et al. Efficient $\mathrm{T}$ cell activation requires an optimal dwell-time of interaction between the TCR and the pMHC complex. Nat Immunol (2001) 2:229-34. doi: 10.1038/ 85286

33. Riquelme E, Carreno LJ, Gonzalez PA, Kalergis AM. The duration of TCR/ pMHC interactions regulates CTL effector function and tumor-killing capacity. Eur J Immunol (2009) 39:2259-69. doi: 10.1002/eji.200939341

34. Robbins PF, Li YF, El-Gamil M, Zhao Y, Wargo JA, Zheng Z, et al. Single and dual amino acid substitutions in TCR CDRs can enhance antigen-specific T cell functions. J Immunol (Baltimore Md 1950) (2008) 180:6116-31. doi: 10.4049/jimmunol.180.9.6116

35. Tan MP, Dolton GM, Gerry AB, Brewer JE, Bennett AD, Pumphrey NJ, et al. Human leucocyte antigen class I-redirected anti-tumour CD4(+) T cells require a higher $\mathrm{T}$ cell receptor binding affinity for optimal activity than CD8 (+) T cells. Clin Exp Immunol (2017) 187:124-37. doi: 10.1111/cei.12828

36. Thomas S, Xue SA, Bangham CR, Jakobsen BK, Morris EC, Stauss HJ. Human $\mathrm{T}$ cells expressing affinity-matured TCR display accelerated responses but fail to recognize low density of MHC-peptide antigen. Blood (2011) 118:319-29. doi: 10.1182/blood-2010-12-326736

37. Irvine DJ, Purbhoo MA, Krogsgaard M, Davis MM. Direct observation of ligand recognition by T cells. Nature (2002) 419:845-9. doi: 10.1038/nature01076

38. Viola A, Salio M, Tuosto L, Linkert S, Acuto O, Lanzavecchia A. Quantitative Contribution of CD4 and CD8 to T Cell Antigen Receptor Serial Triggering. J Exp Med (1997) 186:1775-9. doi: 10.1084/jem.186.10.1775 
39. Glassman CR, Parrish HL, Lee MS, Kuhns MS. Reciprocal TCR-CD3 and CD4 Engagement of a Nucleating pMHCII Stabilizes a Functional Receptor Macrocomplex. Cell Rep (2018) 22:1263-75. doi: 10.1016/j.celrep.2017.12.104

40. Mensali N, Dillard P, Hebeisen M, Lorenz S, Theodossiou T, Myhre MR, et al. NK cells specifically TCR-dressed to kill cancer cells. EBioMedicine (2019) 40:106-17. doi: 10.1016/j.ebiom.2019.01.031

41. Weber KS, Li QJ, Persaud SP, Campbell JD, Davis MM, Allen PM. Distinct CD4+ helper $\mathrm{T}$ cells involved in primary and secondary responses to infection. Proc Natl Acad Sci USA (2012) 109:9511-6. doi: 10.1073/ pnas. 1202408109

42. Persaud SP, Parker CR, Lo WL, Weber KS, Allen PM. Intrinsic CD4+ T cell sensitivity and response to a pathogen are set and sustained by avidity for thymic and peripheral complexes of self peptide and MHC. Nat Immunol (2014) 15:266-74. doi: 10.1038/ni.2822

43. Gai SA, Wittrup KD. Yeast surface display for protein engineering and characterization. Curr Opin Struct Biol (2007) 17:467-73. doi: 10.1016/ j.sbi.2007.08.012

44. Stone JD, Chervin AS, Aggen DH, Kranz DM. T cell receptor engineering. Methods Enzymol (2012) 503:189-222. doi: 10.1016/B978-0-12-3969620.00008-2

45. Bendle GM, Linnemann C, Hooijkaas AI, Bies L, de Witte MA, Jorritsma A, et al. Lethal graft-versus-host disease in mouse models of $\mathrm{T}$ cell receptor gene therapy. Nat Med (2010) 16:565-570, 561p following 570. doi: 10.1038/nm.2128

46. Ghorashian S, Kramer AM, Onuoha S, Wright G, Bartram J, Richardson R, et al. Enhanced CAR T cell expansion and prolonged persistence in pediatric patients with ALL treated with a low-affinity CD19 CAR. Nat Med (2019) 25:1408-14. doi: 10.1038/s41591-019-0549-5

47. Harris DT, Hager MV, Smith SN, Cai Q, Stone JD, Kruger P, et al. Comparison of T Cell Activities Mediated by Human TCRs and CARs That Use the Same Recognition Domains. J Immunol (Baltimore Md 1950) (2018) 200:1088-100. doi: 10.4049/jimmunol.1700236

48. Huang J, Brameshuber M, Zeng X, Xie J, Li QJ, Chien YH, et al. A single peptide-major histocompatibility complex ligand triggers digital cytokine secretion in CD4(+) T cells. Immunity (2013) 39:846-57. doi: 10.1016/ j.immuni.2013.08.036

49. Chervin AS, Stone JD, Bowerman NA, Kranz DM. Cutting edge: inhibitory effects of CD4 and CD8 on T cell activation induced by high-affinity noncognate ligands. J Immunol (Baltimore Md 1950) (2009) 183:7639-43. doi: 10.4049/jimmunol.0901664

50. Chlewicki LK, Holler PD, Monti BC, Clutter MR, Kranz DM. High-affinity, peptide-specific $\mathrm{T}$ cell receptors can be generated by mutations in CDR1, CDR2 or CDR3. J Mol Biol (2005) 346:223-39. doi: 10.1016/j.jmb.2004.11.057

51. Midelfort KS, Hernandez HH, Lippow SM, Tidor B, Drennan CL, Wittrup KD. Substantial energetic improvement with minimal structural perturbation in a high affinity mutant antibody. J Mol Biol (2004) 343:685-701. doi: 10.1016/j.jmb.2004.08.019

52. Richman SA, Kranz DM, Stone JD. Biosensor Detection Systems: Engineering Stable, High-Affinity Bioreceptors by Yeast Surface Display. Methods Mol Biol (Clifton NJ) (2009) 504:323-50. doi: 10.1007/978-1-60327-569-9_19

53. Benatuil L, Perez JM, Belk J, Hsieh CM. An improved yeast transformation method for the generation of very large human antibody libraries. Protein Eng Des Sel (2010) 23:155-9. doi: 10.1093/protein/gzq002

54. Stone JD, Chervin AS, Aggen DH, Kranz DM. T cell receptor engineering. In: KD Wittrup and GL Verdine, editors. Methods in Enzymology: Protein Engineering for Therapeutics, Vol 203, Pt B, vol. 503. San Diego: Elsevier Academic Press Inc (2012). p. 189-222.

55. Daniels MA, Teixeiro E, Gill J, Hausmann B, Roubaty D, Holmberg K. Thymic selection threshold defined by compartmentalization of Ras/MAPK signalling. Nature (2006) 444(7120):724-9. doi: 10.1038/nature05269

56. Savage PA, Boniface JJ, Davis MM. A kinetic basis for T cell receptor repertoire selection during an immune response. Immunity (1999) 10:48592. doi: 10.1016/S1074-7613(00)80048-5

57. Holst J, Szymczak-Workman AL, Vignali KM, Burton AR, Workman CJ, Vignali DA. Generation of T-cell receptor retrogenic mice. Nat Protoc (2006) 1:406-17. doi: 10.1038/nprot.2006.61

58. Holler PD, Holman PO, Shusta EV, O’Herrin S, Wittrup KD, Kranz DM. In vitro evolution of a T cell receptor with high affinity for peptide/MHC. Proc Natl Acad Sci USA (2000) 97:5387-92. doi: 10.1073/pnas.080078297
59. Kim JH, Lee SR, Li LH, Park HJ, Park JH, Lee KY, et al. High cleavage efficiency of a $2 \mathrm{~A}$ peptide derived from porcine teschovirus- 1 in human cell lines, zebrafish and mice. PloS One (2011) 6:e18556. doi: 10.1371/ journal.pone. 0018556

60. Parrish HL, Glassman CR, Keenen MM, Deshpande NR, Bronnimann MP. A Transmembrane Domain GGxxG Motif in CD4 Contributes to Its LckIndependent Function but Does Not Mediate CD4 Dimerization. PloS One (2015) 10:e0132333. doi: 10.1371/journal.pone.0132333

61. Chao G, Lau WL, Hackel BJ, Sazinsky SL, Lippow SM, Wittrup KD. Isolating and engineering human antibodies using yeast surface display. Nat Protoc (2006) 1:755-68. doi: 10.1038/nprot.2006.94

62. Knies D, Klobuch S, Xue SA, Birtel M, Echchannaoui H, Yildiz O, et al. An optimized single chain TCR scaffold relying on the assembly with the native CD3-complex prevents residual mispairing with endogenous TCRs in human T-cells. Oncotarget (2016) 7:21199-221. doi: 10.18632/onco target. 8385

63. Voss RH, Willemsen RA, Kuball J, Grabowski M, Engel R, Intan RS, et al. Molecular design of the Calphabeta interface favors specific pairing of introduced TCRalphabeta in human T cells. J Immunol (Baltimore Md 1950) (2008) 180:391-401. doi: 10.4049/jimmunol.180.1.391

64. Voss RH, Thomas S, Pfirschke C, Hauptrock B, Klobuch S, Kuball J, et al. Coexpression of the T-cell receptor constant alpha domain triggers tumor reactivity of single-chain TCR-transduced human T cells. Blood (2010) 115:5154-63. doi: 10.1182/blood-2009-11-254078

65. Stone JD, Harris DT, Soto CM, Chervin AS, Aggen DH, Roy EJ, et al. A novel $\mathrm{T}$ cell receptor single-chain signaling complex mediates antigen-specific $\mathrm{T}$ cell activity and tumor control. Cancer Immunol Immunother (2014) 63:1163-76. doi: 10.1007/s00262-014-1586-Z

66. Aggen DH, Chervin AS, Schmitt TM, Engels B, Stone JD, Richman SA, et al. Single-chain $\operatorname{V} \alpha \mathrm{V} \beta$ T-cell receptors function without mispairing with endogenous TCR chains. Gene Ther (2012) 19:365-74. doi: 10.1038/ gt.2011.104

67. Aggen DH, Chervin AS, Schmitt TM, Engels B, Stone JD, Richman SA, et al. Single-chain ValphaVbeta T-cell receptors function without mispairing with endogenous TCR chains. Gene Ther (2012) 19:365-74. doi: 10.1038/ gt.2011.104

68. Norment AM, Salter RD, Parham P, Engelhard VH, Littman DR. Cell-cell adhesion mediated by CD8 and MHC class I molecules. Nature (1988) 336:79-81. doi: 10.1038/336079a0

69. Veillette A, Bookman MA, Horak EM, Samelson LE, Bolen JB. Signal transduction through the $\mathrm{CD} 4$ receptor involves the activation of the internal membrane tyrosine-protein kinase p56lck. Nature (1989) 338:257-9. doi: 10.1038/338257a0

70. Parrish HL, Deshpande NR, Vasic J, Kuhns MS. Functional evidence for TCR-intrinsic specificity for MHCII. Proc Natl Acad Sci (2016) 113:3000. doi: 10.1073/pnas.1518499113

71. Killeen N, Littman DR. Helper T-cell development in the absence of CD4-p56 Ick association. Nature (1993) 364:729-32. doi: 10.1038/ $364729 \mathrm{a} 0$

72. Wang JH, Meijers R, Xiong Y, Liu JH, Sakihama T, Zhang R, et al. Crystal structure of the human CD4 N-terminal two-domain fragment complexed to a class II MHC molecule. Proc Natl Acad Sci USA (2001) 98:10799-804. doi: 10.1073/pnas.191124098

73. Yin Y, Wang XX, Mariuzza RA. Crystal structure of a complete ternary complex of T-cell receptor, peptide-MHC, and CD4. Proc Natl Acad Sci (2012) 109:5405. doi: 10.1073/pnas.1118801109

74. Harris DT, Singh NK, Cai Q, Smith SN, Vander Kooi C, Procko E, et al. An Engineered Switch in T Cell Receptor Specificity Leads to an Unusual but Functional Binding Geometry. Structure (2016) 24:1142-54. doi: 10.1016/ j.str.2016.04.011

75. Bowerman NA, Crofts TS, Chlewicki L, Do P, Baker BM, Christopher Garcia K, et al. Engineering the binding properties of the T cell receptor:peptide:MHC ternary complex that governs T cell activity. Mol Immunol (2009) 46:3000-8. doi: 10.1016/j.molimm.2009.06.012

76. Barber EK, Dasgupta JD, Schlossman SF, Trevillyan JM, Rudd CE. The CD4 and CD8 antigens are coupled to a protein-tyrosine kinase (p56lck) that phosphorylates the CD3 complex. Proc Natl Acad Sci (1989) 86:3277-81. doi: $10.1073 /$ pnas.86.9.3277 
77. Love PE, Hayes SM. ITAM-mediated signaling by the T-cell antigen receptor. Cold Spring Harbor Perspect Biol (2010) 2:a002485. doi: 10.1101/ cshperspect.a002485

78. Van Laethem F, Tikhonova AN, Pobezinsky LA, Tai X, Kimura MY, Le Saout C, et al. Lck availability during thymic selection determines the recognition specificity of the $\mathrm{T}$ cell repertoire. Cell (2013) 154:1326-41. doi: 10.1016/j.cell.2013.08.009

79. Van Laethem F, Tikhonova AN, Singer A. MHC restriction is imposed on a diverse $\mathrm{T}$ cell receptor repertoire by $\mathrm{CD} 4$ and $\mathrm{CD} 8$ co-receptors during thymic selection. Trends Immunol (2012) 33:437-41. doi: 10.1016/j.it.2012.05.006

80. Horkova V, Drobek A, Mueller D, Gubser C, Niederlova V, Wyss L, et al. Dynamics of the Coreceptor-LCK Interactions during T Cell Development Shape the Self-Reactivity of Peripheral CD4 and CD8 T Cells. Cell Rep (2020) 30:1504-14.e1507. doi: 10.1073/pnas.1913334117

81. Wei Q, Brzostek J, Sankaran S, Casas J, Hew LS-Q, Yap J, et al. Lck bound to coreceptor is less active than free Lck. Proc Natl Acad Sci USA (2020) 117:15809-17. doi: 10.1073/pnas.1913334117

82. Gascoigne NRJ, Casas J, Brzostek J, Rybakin V. Initiation of TCR phosphorylation and signal transduction. Front Immunol (2011) 2:72-2. doi: 10.3389/fimmu.2011.00072

83. Jiang N, Huang J, Edwards LJ, Liu B, Zhang Y, Beal CD, et al. Two-stage cooperative $\mathrm{T}$ cell receptor-peptide major histocompatibility complex-CD8 trimolecular interactions amplify antigen discrimination. Immunity (2011) 34:13-23. doi: 10.1016/j.immuni.2010.12.017

84. van der Merwe PA, Cordoba SP. Late arrival: recruiting coreceptors to the T cell receptor complex. Immunity (2011) 34:1-3. doi: 10.1016/j.immuni.2011.01.001

85. Filipp D, Julius M. Lipid rafts: resolution of the "fyn problem"? Mol Immunol (2004) 41:645-56. doi: 10.1016/j.molimm.2004.04.011

86. Haughn L, Gratton S, Caron L, Sekaly RP, Veillette A, Julius M. Association of tyrosine kinase p56lck with CD4 inhibits the induction of growth through the alpha beta T-cell receptor. Nature (1992) 358:328-31. doi: 10.1038/358328a0

87. Presotto D, Erdes E, Duong MN, Allard M, Regamey P-O, Quadroni M, et al. Fine-Tuning of Optimal TCR Signaling in Tumor-Redirected CD8 T Cells by Distinct TCR Affinity-Mediated Mechanisms. Front Immunol (2017) 8:1564-4. doi: 10.3389/fimmu.2017.01564

88. Stepanek O, Prabhakar Arvind S, Osswald C, King Carolyn G, Bulek A, Naeher $\mathrm{D}$, et al. Coreceptor Scanning by the T Cell Receptor Provides a Mechanism for T Cell Tolerance. Cell (2014) 159:333-45. doi: 10.1016/j.cell.2014.08.042

89. Wang Q, Strong J, Killeen N. Homeostatic competition among T cells revealed by conditional inactivation of the mouse Cd4 gene. J Exp Med (2001) 194:1721-30. doi: 10.1084/jem.194.12.1721

90. Kersh GJ, Kersh EN, Fremont DH, Allen PM. High- and low-potency ligands with similar affinities for the TCR: the importance of kinetics in TCR signaling. Immunity (1998) 9:817-26. doi: 10.1016/S1074-7613(00)80647-0

91. Bonnard M, Haughn L, Julius M. CD4-mediated inhibiton of IL-2 production in activated T cells. J Immunol (Baltimore Md 1950) (1999) 162:1252-60.

92. Harris DT, Kranz DM. Adoptive T Cell Therapies: A Comparison of T Cell Receptors and Chimeric Antigen Receptors. Trends Pharmacol Sci (2016) 37:220-30. doi: 10.1016/j.tips.2015.11.004

93. James JR. Tuning ITAM multiplicity on T cell receptors can control potency and selectivity to ligand density. Sci Signaling (2018) 11:eaan1088. doi: 10.1126/scisignal.aan1088

94. Moritz D, Wels W, Mattern J, Groner B. Cytotoxic T lymphocytes with a grafted recognition specificity for ERBB2-expressing tumor cells. Proc Natl Acad Sci USA (1994) 91:4318-22. doi: 10.1073/pnas.91.10.4318

95. Sebestyén Z, Schooten E, Sals T, Zaldivar I, San José E, Alarcón B, et al. Human TCR that incorporate CD3zeta induce highly preferred pairing between TCRalpha and beta chains following gene transfer. J Immunol (Baltimore Md 1950) (2008) 180:7736-46. doi: 10.4049/jimmunol.180.11.7736

96. Haga-Friedman A, Horovitz-Fried M, Cohen CJ. Incorporation of Transmembrane Hydrophobic Mutations in the TCR Enhance Its Surface Expression and T Cell Functional Avidity. J Immunol (2012) 188:5538-46. doi: 10.4049/jimmunol.1103020
97. Deniger DC, Pasetto A, Tran E, Parkhurst MR, Cohen CJ, Robbins PF, et al. Stable, Nonviral Expression of Mutated Tumor Neoantigen-specific T-cell Receptors Using the Sleeping Beauty Transposon/Transposase System. Mol Ther (2016) 24:1078-89. doi: 10.1038/mt.2016.51

98. Gros A, Parkhurst MR, Tran E, Pasetto A, Robbins PF, Ilyas S, et al. Prospective identification of neoantigen-specific lymphocytes in the peripheral blood of melanoma patients. Nat Med (2016) 22:433-8. doi: 10.1038/nm.4051

99. Weinkove R, George P, Dasyam N, McLellan AD. Selecting costimulatory domains for chimeric antigen receptors: functional and clinical considerations. Clin Transl Immunol (2019) 8:e1049-9. doi: 10.1002/ cti2.1049

100. Weinkove R, George P, Dasyam N, McLellan AD. Combined CD28 and 41BB Costimulation Potentiates Affinity-tuned Chimeric Antigen Receptorengineered T Cells. Clin Cancer Res (2019) 8(5):e1049-e. doi: 10.1158/10780432.Ccr-18-2559

101. Drent E, Poels R, Ruiter R, van de Donk NWCJ, Zweegman S, Yuan H, et al. Phosphoproteomic analysis of chimeric antigen receptor signaling reveals kinetic and quantitative differences that affect cell function. Sci Signal (2018) 11:4014-25. doi: 10.1126/scisignal.aat6753

102. Kofler DM, Chmielewski M, Rappl G, Hombach A, Riet T, Schmidt A, et al. CD28 costimulation Impairs the efficacy of a redirected t-cell antitumor attack in the presence of regulatory $t$ cells which can be overcome by preventing Lck activation. Mol Ther J Am Soc Gene Ther (2011) 19:760-7. doi: 10.1038/mt.2011.9

103. Long AH, Haso WM, Shern JF, Wanhainen KM, Murgai M, Ingaramo M, et al. 4-1BB costimulation ameliorates $\mathrm{T}$ cell exhaustion induced by tonic signaling of chimeric antigen receptors. Nat Med (2015) 21:581-90. doi: $10.1038 / \mathrm{nm} .3838$

104. Fragoso R, Ren D, Zhang X, Su MW, Burakoff SJ, Jin YJ. Lipid raft distribution of $\mathrm{CD} 4$ depends on its palmitoylation and association with Lck, and evidence for CD4-induced lipid raft aggregation as an additional mechanism to enhance CD3 signaling. I Immunol (Baltimore Md 1950) (2003) 170:913-21. doi: 10.4049/jimmunol.170.2.913

105. Tavano R, Contento RL, Baranda SJ, Soligo M, Tuosto L, Manes S, et al. $\mathrm{CD} 28$ interaction with filamin-A controls lipid raft accumulation at the Tcell immunological synapse. Nat Cell Biol (2006) 8:1270-6. doi: 10.1038/ ncb1492

106. Ramos CA, Rouce R, Robertson CS, Reyna A, Narala N, Vyas G, et al. In Vivo Fate and Activity of Second- versus Third-Generation CD19-Specific CAR-T Cells in B Cell Non-Hodgkin's Lymphomas. Mol Ther J Am Soc Gene Ther (2018) 26:2727-37. doi: 10.1016/j.ymthe.2018.09.009

107. Gomes da Silva D, Mukherjee M, Srinivasan M, Dakhova O, Liu H, Grilley B, et al. Direct Comparison of In Vivo Fate of Second and Third-Generation CD19-Specific Chimeric Antigen Receptor (CAR)-T Cells in Patients with BCell Lymphoma: Reversal of Toxicity from Tonic Signaling. Blood (2016) 128:1851-1. doi: 10.1182/blood.V128.22.1851.1851

108. Richman SA, Aggen DH, Dossett ML, Donermeyer DL, Allen PM, Greenberg PD, et al. Structural features of $\mathrm{T}$ cell receptor variable regions that enhance domain stability and enable expression as single-chain ValphaVbeta fragments. Mol Immunol (2009) 46:902-16. doi: 10.1016/ j.molimm.2008.09.021

Conflict of Interest: The authors declare that the research was conducted in the absence of any commercial or financial relationships that could be construed as a potential conflict of interest.

Copyright (C) 2021 Johnson, Magoffin, Myers, Finnell, Hancock, Orton, Persaud, Christensen and Weber. This is an open-access article distributed under the terms of the Creative Commons Attribution License (CC BY). The use, distribution or reproduction in other forums is permitted, provided the original author(s) and the copyright owner(s) are credited and that the original publication in this journal is cited, in accordance with accepted academic practice. No use, distribution or reproduction is permitted which does not comply with these terms. 